\title{
EVOLUÇÃO MAGMÁTICA DA INTRUSÃO BÁSICA NO POÇO 1UN30 E SUA INTERAÇÃO COM O ARENITO ENCAIXANTE, NA PORÇÃO NORTE DA BACIA DO PARNAÍBA (N E NE DO BRASIL)
}

\author{
MAGMATIC EVOLUTION OF BASIC INTRUSION IN THE WELL IUN3O AND ITS \\ INTERACTION WITH THE ENCLOSING SANDSTONE, IN THE NORTHERN OF THE \\ PARNAÍBA BASIN
}

\section{Juliana Ferreira GODOT SOUZA ${ }^{1}$, Cícera Neysi de ALMEIDA ${ }^{2}$, Reiner NEUMANN ${ }^{3}$, Leonardo Fonseca BORGHI DE ALMEIDA², Julio Cezar MENDES ${ }^{1}$, Silvia Regina de MEDEIROS ${ }^{1}$, Sérgio Castro VALENTE ${ }^{4}$ Alan Wanderley de Albuquerque MIRANDA ${ }^{4}$, Artur CORVAL ${ }^{4}$, Francisco de Assis NEGRI ${ }^{5}$}

${ }^{1}$ Universidade Federal do Rio de Janeiro. Graduação em Geologia. Avenida Athos da Silveira Ramos, 274 - Cidade Universitária, Ilha do Fundão. Rio de Janeiro - RJ. E-mail: julianagodot@ hotmail.com

${ }^{2}$ Universidade Federal do Rio de Janeiro. Departamento de Geologia. CCMN. Avenida Athos da Silveira Ramos, 274 - Cidade Universitária, Ilha do Fundão Rio de Janeiro - RJ. E-mails: neysi@geologia.ufrj.br, lborghi@geologia.ufrj.br;

julio@geologia.ufrj.br; silvia@geologia.ufrj.br

${ }^{3}$ CETEM Centro de Tecnologia Mineral, Coordenação de Análises Minerais, Setor de Caracterização Tecnológica. Avenida Pedro Calmon, 900 - Cidade Universitária, Ilha do Fundão. Rio de Janeiro - RJ.

E-mail: rneumann@cetem.gov.br

${ }^{4}$ Universidade Federal Rural do de Janeiro. Instituto de Agronomia, Departamento de Geociências.Rodovia BR 465 Km 7. Cidade Universitária. Seropédica - RJ.

E-mails: sergio@ufrrj.br; alanmirandageo@gmail.com; corvalgeo98@gmail.com

${ }^{5}$ Instituto Geológico do Estado de São Paulo, Centro de Geologia e Meio Ambiente. Avenida Miguel Stéfano, 3900. Água Funda. São Paulo - SP.E-mail: negri.francisco@gmail.com

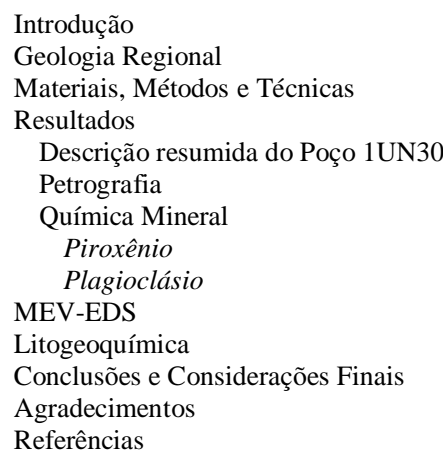

RESUMO - Este trabalho desenvolveu-se através dos resultados das análises petrográficas, químicas e litogeoquímicas do testemunho do poço 1UN30, perfurado na Bacia do Parnaíba. A petrografia aponta: a rocha ígnea como de textura glomeroporfirítica e mineralogia essencial de plagioclásio e piroxênio, com olivina e minerais opacos acessórios; o arenito como quartzo arenito a subarcóseo com arcabouço de quartzo, K-feldspato e minerais opacos, e interstícios preenchidos por tremolita e argilominerais. A rocha ígnea, pela litogeoquímica, é um basalto tolético intraplaca. Análises em MEV no arenito apontaram os argilominerais como do grupo ilita-esmectita e identificaram minerais do grupo da clorita. Pelas texturas e química dos grãos, identifica-se duas fases de formação de plagioclásio. Uma mais cálcica ocorre como núcleos corroídos, zonados e de textura peneira grossa. A outra consiste nas bordas dos núcleos corroídos ou em cristais isolados, zonados e com textura peneira fina. Conclui-se que a rocha foi formada por quatro eventos evolutivos: primeira fase de cristalização; descompressão rápida, durante a ascensão da câmera magmática; mistura com magma mais quente, rico em cálcio; e segunda fase de cristalização. A interação com o magma formou tremolita e argilominerais no arenito encaixante, com preservação do aspecto sedimentar prévio, em um processo denominado diagênese de contato.

Palavras-chave: Bacia do Parnaíba, Formação Sardinha, Basalto, Evolução magmática, Diagênese de Contato.

\begin{abstract}
This work was developed as a result of petrographic, chemical and litogeochemical analysis of the 1 UN30 well, drilled in the Parnaíba Basin. The petrography indicates that the igneous rock has glomeroporphyrytic texture and essential mineralogy of plagioclase and pyroxene with olivine and opaque minerals as accessories. The sandstone is a quartzarenite to subarkose with framework of the quartz, $\mathrm{K}$ feldspar and opaque minerals, and interstices filled by tremolite and clay minerals. The igneous rock, by litogeochemical, is an intraplate tholeiitic basalt. Analysis of MEV pointed the clay minerals as belonging to the illite-smectite group and identified minerals of chlorite group. Through the textures and chemical analysis of the grains, two phases of plagioclase formation are identified. The most calcic phase occurs as corroded and zoned core with thick sieve textured. The other consists at the edges of corroded cores or in isolated crystals, zoned and with fine sieve texture. It concludes that the rock was formed by four evolutionary events: the first phase of crystallization; rapid decompression during rising of the magma chamber; mix with a warmer and rich in calcium magma; and the second phase of crystallization. The interaction with the magma formed tremolite and clay minerals in the sandstone, maintaining the anterior sedimentary aspect, in a process called contact diagenesis. Keywords: Parnaíba Basin, Sardinha Formation, Basalt, Magmatic Evolution, Contact Diagenesis.
\end{abstract}




\section{INTRODUÇÃO}

Localizada no Nordeste do Brasil, a Bacia do Parnaíba é constituída por sucessões sedimentares cortadas por intrusões basálticas que se apresentam sob a forma de diques e soleiras e compreendem à Formação do Mosquito, de idade triássica/jurássica, e à Formação Sardinha, de idade cretácea (Almeida et al., 2000). Esta associação de rochas ígneas e sedimentares está relacionada com sistemas petrolíferos não convencionais, onde as intrusões magmáticas desempenham um papel de catalisador na geração de hidrocarbonetos, além de servirem na sua vedação e retenção (Abelha, 2013).

Trabalhos anteriores acerca do magmatismo na Bacia do Parnaíba abordam principalmente dados obtidos a partir de amostras de superfície (eg. Bellieni et al., 1990; Merle et al., 2011), havendo unicamente o trabalho de da Silva et al. (2017) que trata amostras de subsuperfície. Seu número é, portanto, insuficiente dada a importância econômica dessas rochas. Para suprir essa demanda, o presente artigo apresenta novos dados petrográficos, litogeoquímicos e de química mineral obtidos a partir da análise do testemunho de um poço (1UN30) perfurado anteriormente pelo Projeto Carvão da Bacia do Parnaíba (1975) realizado pela CPRM (Serviço Geológico do Brasil). Tais dados permitiram o estudo da evolução magmática da intrusão de rocha básica reconhecida no poço, além da interação desta com $o$ arenito encaixante. Conhecimentos considerados de grande importância para a melhor compreensão dos sistemas petrolíferos da Bacia do Parnaíba.

\section{GEOLOGIA REGIONAL}

A bacia do Parnaíba é uma bacia intracratônica fanerozóica localizada no Norte/Nordeste do Brasil, nos estados do Piauí, Maranhão, Tocantins e Pará (Almeida et al., 2000). Compreende uma extensa área deposicional com cerca de $600.000 \mathrm{~km}^{2}$ de extensão e aproximadamente $3.500 \mathrm{~m}$ de espessura em seu depocentro (Vaz et al., 2007).

Sua evolução litoestratigráfica começou no final do Cambriano/início do Ordoviciano com a deposição de sedimentos siliciclásticos imaturos (Grupo Jaibaras) sobre riftes e grábens, recémformados no contexto do rifteamento de Laurentia e Báltica (Bond et al., 1984; Oliveira \& Mohriak, 2003). Segundo Goes et al. (1990), a Bacia do Parnaíba pode ser dividida em quatro supersequências sedimentares separadas por discordâncias regionais bem marcadas. Na porção basal há a sequência siluro-ordoviciana (Grupo Serra Grande), a sequência devoniana (Grupo Carindé) e a sequência carbonífero-permiana (porção basal do Grupo Balsas). Associadas a elas, houve dois episódios de intenso magmatismo básico correlacionáveis com eventos de ruptura de supercontinentes. $\mathrm{O}$ primeiro ocorrido no Triássico-Jurássico (Formação Mosquito) gerou também áreas de acomodação onde depositaram-se os sedimentos clásticos que compõe a Formação Pastos Bons. O segundo episódio data do Cretáceo e constitui a Formação Sardinha. Sobrepostos a esses cinco eventos, há a sequência cretácea, cuja deposição associa-se a ciclos transgressivos correlacionados à abertura do Oceano Atlântico Sul.

$\mathrm{Na}$ análise estrutural da Bacia do Parnaíba destacam-se três feições morfo-estruturais principais, os lineamentos Picos-Santa Inês (NWSE), Transbrasiliano (NE-SW) e TocantinsAraguaia (N-S; Oliveira \& Mohriak, 2003). Durante sua evolução, desde o Ordoviciano até o início do Carbonífero, as direções dos eixos deposicionais foram controladas por fraturas e falhas herdadas do embasamento. A partir deste período, houve um deslocamento dos depocentros da bacia para sua porção central e o padrão de sedimentação passou a ser concêntrico até o Jurássico. A forma externa da bacia assumiu uma morfologia ovalada, típica do tipo sinéclise (Vaz et al., 2007).

\section{MATERIAIS, MÉTODOS E TÉCNICAS}

O material analisado são amostras coletadas em diferentes profundidades do poço 1UN30, perfurado no município de Anapurus (MA) pelo Projeto Carvão da Bacia do Parnaíba (1975) realizado pela CPRM (Serviço Geológico do Brasil). O testemunho do poço (Figura 1) encontra-se alocado na litoteca do $4^{\circ}$ distrito do
DNPM (Departamento Nacional de Pesquisa Mineral), na cidade de Recife, estado de Pernambuco (Brasil). As amostras coletadas são quatro (Figura 1). Duas da intrusão ígnea e duas da rocha sedimentar encaixante na região próxima ao contato. As profundidades são, respectivamente, $380,20 \mathrm{~m}, 380,00 \mathrm{~m}, 379,85 \mathrm{~m}$ e $379,50 \mathrm{~m}$. 


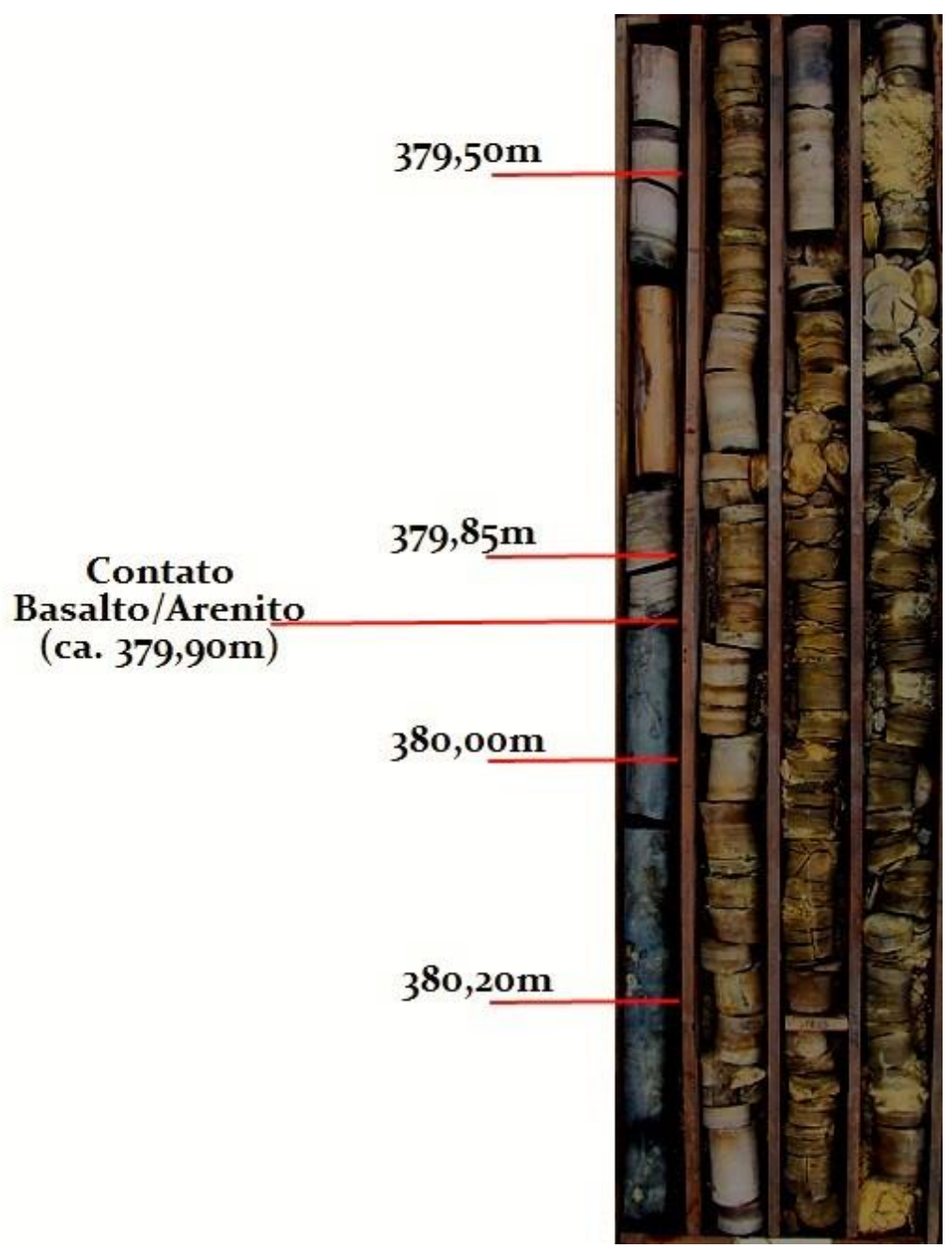

Figura 1 - Foto do testemunho do poço 1UN30 com as profundidades das amostras coletadas e o contato com a intrusão destacados.

A análise petrográfica consistiu na descrição analíticas da microssonda foram: voltagem de das quatro lâminas em microscópico óptico de luz polarizada do modelo Carl Zeiss Axio imager A.1. Para as lâminas de rocha ígneas, os aspectos observados e identificados foram granulação, textura, mineralogia e índice de cor. Devido à granulação fina das rochas não foi possível determinar sua composição modal. Já na descrição das lâminas sedimentares identificouse a granulometria, angulosidade dos grãos, tipos de contatos e composição mineralógica da rocha. Sua classificação baseou-se no diagrama de Dott (1964). Para o estudo da química mineral, revestiu-se as lâminas com uma película de carbono e então empregou-se as técnicas analíticas de microssonda eletrônica (JEOL, modelo JXA 8230) e MEV-EDS (Microscopia Eletrônica de Varredura acoplada com microanálise química por fluorescência de raios $\mathrm{X})$.

As duas lâminas de rocha magmática foram submetidas à microssonda eletrônica, onde visou-se a amostragem química da olivina, do piroxênio e do plagioclásio. As condições $15 \mathrm{KeV}$, corrente de $20 \mathrm{nA}$, diâmetro de feixe de 1 micrômetro e correção ZAF O conteúdo de $\mathrm{SiO}_{2}, \mathrm{Al}_{2} \mathrm{O}_{3}, \quad \mathrm{FeO}, \quad \mathrm{CaO}, \mathrm{Na}_{2} \mathrm{O}$ e $\mathrm{K}_{2} \mathrm{O}$ foi analisado para o plagioclásio e de $\mathrm{SiO}_{2}, \mathrm{Al}_{2} \mathrm{O}_{3}$, $\mathrm{TiO}_{2}, \mathrm{FeO}_{\mathrm{t}}, \mathrm{MgO}, \mathrm{MnO}, \mathrm{CaO}$ e $\mathrm{Cr}_{2} \mathrm{O}_{3}$ para os cristais de piroxênio. $\mathrm{O}$ avançado estado de alteração da olivina impediu a sua análise e dificultou a análise de piroxênio. No total, foram analisados cinco cristais de piroxênio pertencente à matriz, com pontos feitos na borda e no núcleo dos grãos. No entanto, apenas foram considerados resultados satisfatórios (mais de 95\% de confiabilidade) em 6 dos 10 pontos realizados (Tabela 1). Quanto ao plagioclásio, analisou-se 14 fenocristais, com amostragem de perfil para os grãos que apresentavam zoneamento e de borda e núcleo para os demais (Tabela 2). Todos os pontos de plagioclásio apresentaram resultados satisfatórios. Os padrões de plagioclásio estavam de acordo com Plagioclase An-65 (Astimex Scientific Limited) e os de piroxênio segundo o Cr-Augita Smithsonian. 

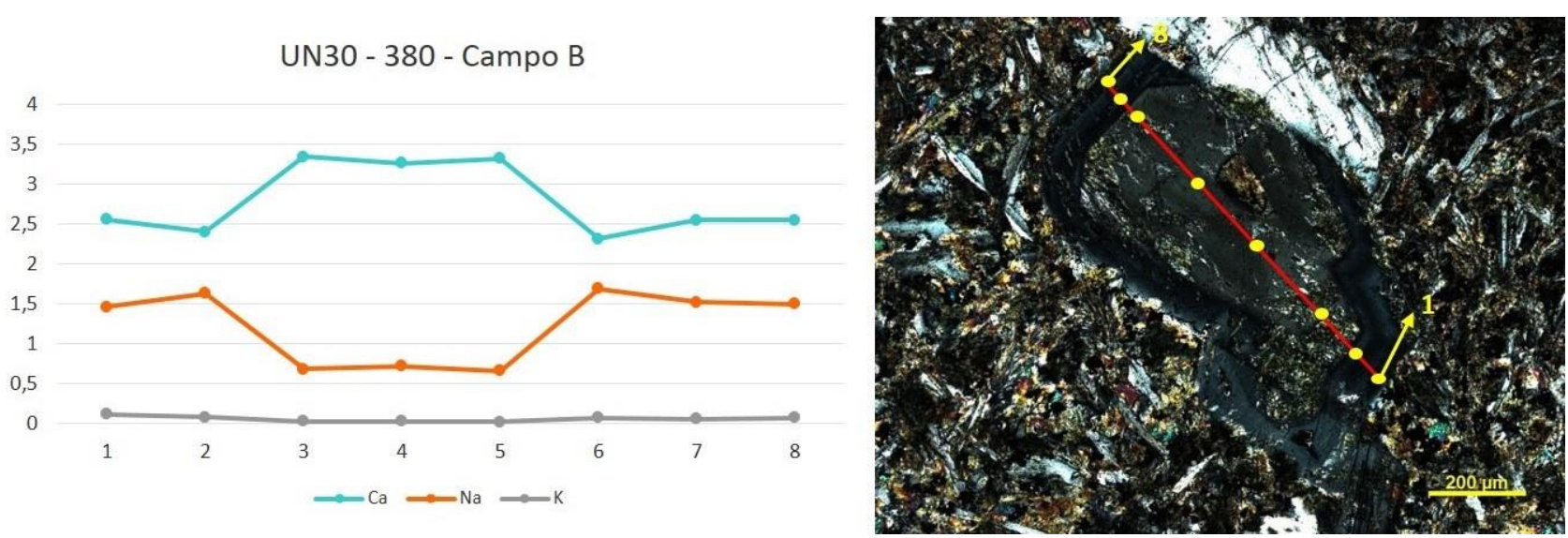

Figura 2 - Gráfico da composição química, considerando Ca, Na e K, de plagioclásio zonado ao longo de uma seção de pontos amostrados.

O método MEV-EDS, com equipamento de modelo FEI Quanta 400, foi empregado para a análise e melhor identificação dos minerais localizados nos interstícios da lâmina da rocha encaixante de profundidade $379,50 \mathrm{~m}$. A lâmina de rocha sedimentar da região mais próxima ao contato não foi submetida a análise.

Posteriormente, as sobras da laminação das amostras de rocha ígnea foram preparadas (britadas e moídas até a transformação destas em um pó homogêneo) e enviadas ao Activation Laboratories
LTD (ACTLABS), em Ontário (Canadá), onde foram realizadas as análises litogeoquímicas de rocha total para elementos maiores $\left(\mathrm{SiO}_{2}, \mathrm{TiO}_{2}\right.$, $\mathrm{Al}_{2} \mathrm{O}_{3}, \mathrm{Fe}_{2} \mathrm{O}_{3}, \mathrm{MnO}, \mathrm{MgO}, \mathrm{CaO}, \mathrm{Na}_{2} \mathrm{O}, \mathrm{K}_{2} \mathrm{O}$, $\mathrm{P}_{2} \mathrm{O}_{5}$ ), de elementos-traço ( $\mathrm{Rb}, \mathrm{Ba}, \mathrm{Sr}, \mathrm{U}, \mathrm{Th}, \mathrm{Nb}$, $\mathrm{Y}, \mathrm{Zr}, \mathrm{Hf}, \mathrm{Sc}, \mathrm{Cr}$ e Ni) e de elementos terras raras (ETR) pelo método ICP-MS (Inductively Coupled Plasma - Mass Spectrometry). Com os dados litogeoquímicos obtidos, foram gerados diagramas de classificação, de ambiência geotectônica e spidergrams no software GCDkit.

\section{RESULTADOS}

\section{Descrição resumida do Poço 1UN30}

$\mathrm{O}$ poço $1 \mathrm{UN} 30$ possui uma profundidade perfurada de $383,30 \mathrm{~m}$. Segundo os testemunhos analisados (Figura 3), os primeiros 40,00m são preenchidos por sedimentos arenosos inconsolidados. Depois seguem-se intercalações de argilitos, siltitos e folhelhos com arenitos finos a muito finos, e localmente arenitos médios que raramente apresentam estratificação cruzada. Neste intervalo, as camadas mais finas são mais abundantes no topo que na base. A uma profundidade de $379,90 \mathrm{~m}$ observa-se o contato dessas sucessões com a rocha ígnea, que conta com uma espessura perfurada de $3,40 \mathrm{~m}$. O corpo magmático é caracterizado por uma rocha de coloração cinza escura e ocasionais faixas de pirita.

Descrições prévias do poço realizadas pelo Projeto Carvão da Bacia do Parnaíba (1975) classificam o intervalo inconsolidado do topo como pertencente ao Terciário. As sucessões arenosas e lamíticas mais rasas, onde predomina a fração mais fina com arenitos médios a finos, são da Formação Itapecuru, enquanto as sucessões basais pertencem à Formação Cabeças. A intrusão ígnea é descrita como pertencente à
Formação Sardinha.

\section{Petrografia}

A petrografia das lâminas da intrusão aponta uma rocha melanocrática (IC ca. 65\%), hipocristalina (com 5\% de vidro) e hipidiomórfica a xenomórfica que apresenta textura glomeroporfirítica, com $10 \%$ de fenocristais. A matriz possui texturas diversas, incluindo ofítica, subofítica, intergranular e intersetal. A mineralogia da rocha consiste em plagioclásio e piroxênio (clino e orto) como minerais essenciais; olivina e minerais opacos como acessórios; e talco, serpentina, bowlingita, iddingsita, uralita, clorita, epidoto e leucoxênio como produtos de alteração.

Os fenocristais são de plagioclásio, olivina e clinopiroxênio e ocorrem, respectivamente, com proporções de $92 \%, 2 \%$ e $6 \%$ em relação ao total de fenocristais. A fase predominante é plagioclásio $(5,0-1,0 \mathrm{~mm})$ que se apresenta como cristais tabulares euédricos a subédricos em aglomerados com o piroxênio ou de forma isolada. Os grãos geralmente apresentam zoneamento, corrosão, alteração para caolinita e feições de peneira (fina e grossa), syneusesis e textura tipo esponja. Os fenocristais de clino- 


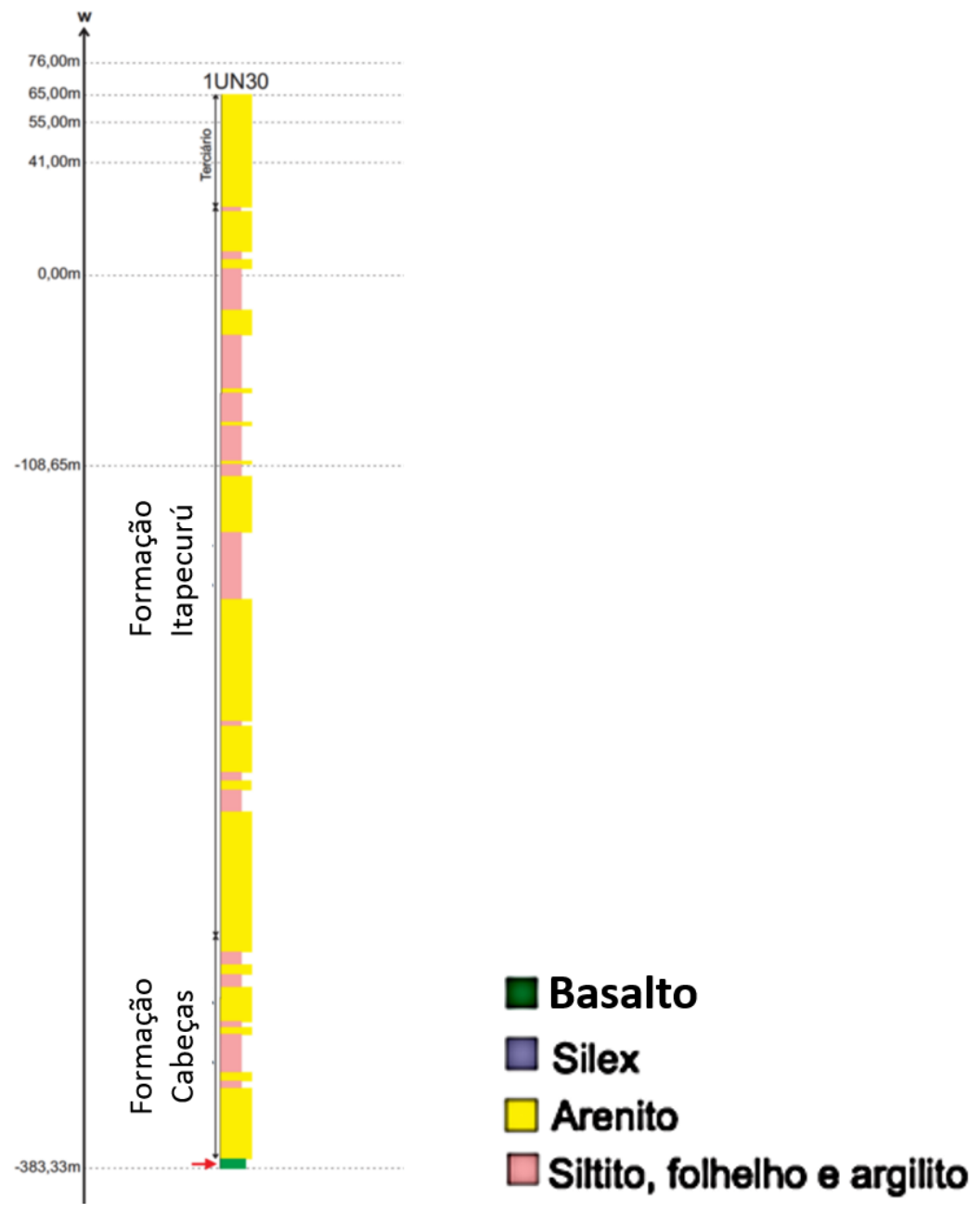

Figura 3 - Perfil esquemático do poço 1UN30.

piroxênio $(0,5-0,8 \mathrm{~mm})$ ocorrem como cristais anédricos com pleocroísmo incolor a verde, relevo alto cores de interferência azul a rosa de terceira ordem e localmente com coloração verde amarronzada decorrente da alteração. Eles apresentam-se isolados ou em aglomerados e estão levemente alterados para epidoto, clorita e uralita. Olivina $(0,2-1,2 \mathrm{~mm})$ ocorre unicamente como fenocristais isolados subédricos a anédricos de hábito granular e alterados para talco, serpentina, bowlingita e iddigsita.

$\mathrm{Na}$ matriz, os grãos de plagioclásio $(0,1-0,8$ $\mathrm{mm}$ ) são incolores, de relevo baixo, cor de interferência baixa, euédricos a subédricos e têm hábito tabular. Além disso apresentam zoneamento, corrosão e raras fraturas. Na matriz foram observados dois tipos de piroxênio $(0,1-0,2$ $\mathrm{mm}$ ): clinopiroxênio e ortopiroxênio (numa proporção aproximada de 85/15). Esses dois tipos possuem características similares e por esta razão não foram descritos separadamente. Eles possuem coloração verde, com relevo alto, pleocroísmo de incolor a verde, cor de interferência variando de tons de amarelo e alaranjado (OPX) e coloração azul a rosa (CPX) de segunda ordem e raramente apresentam duas direções de clivagem. São anédricos, granulares e exibem forte alteração nas bordas para uralita e epidoto, estando apenas o núcleo preservado.Os minerais opacos $(0,05-0,2$ $\mathrm{mm}$ ) ocorrem como grãos subédricos a anédricos, geralmente em agregados e localmente isolados, alterados para leucoxênio. A composição modal aproximada da matriz indica que esta é composta principalmente por plagioclásio $(52 \%)$ e piroxênio (40\%), com minerais opacos subordinados (8\%).

$\mathrm{O}$ arenito possui granulometria fina a muito fina com grãos subangulosos a subarredondados apresentando contatos tangenciais e suturados. É classificado como quartzo arenito a subarcóseo (Figura 4), possuindo arcabouço de quartzo, Kfeldspato e minerais opacos. Em seus interstícios, observa-se a presença de minerais fibrosos $(0,05-$ $0,1 \mathrm{~mm}$ ) com cores de interferência elevadas, relevo alto, leve pleocroísmo em tons de verde claro a incolor e duas direções de clivagem formando um ângulo de $60^{\circ}$ identificados como tremolita. Também se observou argilominerais, identificados como grãos submilimétricos, de cores de interferência altas e relevo baixo, organizados em aglomerados. 


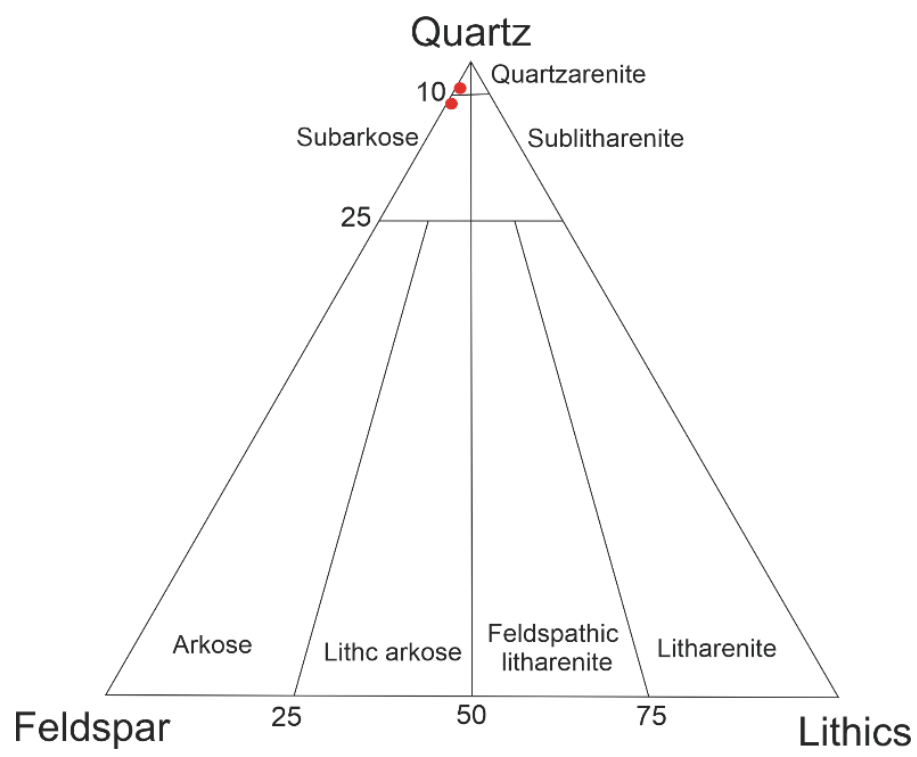

\section{Química Mineral}

Figura 4 - Diagrama de classificação de Arenitos (Dott, 1964).

Os resultados analíticos obtidos em estruturais calculadas encontram-se listados nas microssonda eletrônica para piroxênio e tabelas 1 e 2 abaixo.

Tabela 1 - Resultados da análise química do piroxênio utilizando microssonda eletrônica.

\begin{tabular}{|c|c|c|c|c|c|c|c|c|c|c|c|c|c|c|}
\hline Lâmina & number & $\mathrm{Al}_{2} \mathrm{O}_{3}$ & MgO & $\mathrm{Na}_{2} \mathrm{O}$ & $\mathrm{SiO}_{2}$ & $\mathrm{FeO}$ & $\mathrm{CaO}$ & $\mathrm{TiO}_{2}$ & MnO & $\mathrm{Cr}_{2} \mathrm{O}_{3}$ & Total & $\% \mathrm{CaO}$ & \% MgO & $\% \mathrm{FeO}$ \\
\hline 1UN30_380 & PX_CF_1N & 5,981 & 11,463 & 0,876 & 48,83 & 15,791 & 11,348 & 0,453 & 0,136 & 0,024 & 94,902 & $29 \%$ & $30 \%$ & $41 \%$ \\
\hline 1UN30_380 & PX_CF_1B & 5,24 & 9,774 & 0,099 & 39,141 & 26,219 & 6,46 & 0,041 & 0,133 & 0 & 87,107 & - & - & - \\
\hline 1UN30_380 & PX_CF_2N & 12,009 & 11,263 & 0,077 & 40,971 & 20,292 & 0,056 & 2,178 & 0,08 & 0 & 86,926 & - & - & - \\
\hline 1UN30_380 & PX_CF_2B & 12,287 & 11,426 & 0,106 & 39,24 & 20,609 & 0,05 & 2,792 & 0,08 & 0 & 86,59 & - & - & - \\
\hline 1UN30_380.20 & PX_CH_1N & 3,867 & 15,201 & 0,149 & 50,404 & 10,95 & 18,152 & 0,344 & 0,241 & 0,003 & 99,311 & $41 \%$ & $34 \%$ & $25 \%$ \\
\hline 1UN30_380.20 & PX_CH_1B & 3,516 & 15,295 & 0,127 & 51,05 & 10,468 & 18,989 & 0,362 & 0,224 & 0,009 & 100,04 & $42 \%$ & $34 \%$ & $23 \%$ \\
\hline 1UN30_380.20 & PX_CG_1N & 4,729 & 9,046 & 0,452 & 48,221 & 21,064 & 11,126 & 0,173 & 0,194 & 0,009 & 95,014 & $27 \%$ & $22 \%$ & $51 \%$ \\
\hline 1UN30_380.20 & PX_CG_1B & 3,7 & 14,504 & 0,25 & 49,838 & 13,393 & 16,393 & 0,256 & 0,229 & 0,025 & 98,588 & $37 \%$ & $33 \%$ & $30 \%$ \\
\hline 1UN30_380.20 & PX_Cl_1N & 4,101 & 10,649 & 0,314 & 50,749 & 19,923 & 11,229 & 0,202 & 0,28 & 0 & 97,447 & $27 \%$ & $25 \%$ & $48 \%$ \\
\hline 1UN30_380.20 & PX_Cl_1B & 13,847 & 11,166 & 0,096 & 34,222 & 23,292 & 0,509 & 0,362 & 0,089 & 0 & 83,583 & - & - & - \\
\hline
\end{tabular}

Tabela 2 - Resultados da análise química do plagioclásio utilizando microssonda eletrônica.

\begin{tabular}{|c|c|c|c|c|c|c|c|c|c|c|c|}
\hline Number & $\mathrm{Na}_{2} \mathrm{O}$ & $\mathrm{Al}_{2} \mathrm{O}_{3}$ & $\mathrm{SiO}_{2}$ & $\mathrm{CaO}$ & $\mathrm{K}_{2} \mathrm{O}$ & $\mathrm{FeO}$ & Total & Coluna1 & $\%$ Alb & $\%$ Arn & $\%$ Ort \\
\hline CA_PLA_01_P1 & 4,666 & 30,069 & 52,577 & 11,903 & 0,733 & 1,218 & 101,166 & CA_PLA_01_P1 & $27 \%$ & $69 \%$ & $4 \%$ \\
\hline CA_PLA_01_P2 & 3,934 & 29,094 & 51,028 & 12,273 & 0,474 & 3,131 & 99,934 & _CA_PLA_01_P2 & $24 \%$ & $74 \%$ & $3 \%$ \\
\hline CA_PLA_01_P3 & 3,975 & 29,983 & 52,323 & 12,906 & 0,347 & 1,051 & 100,585 & _CA_PLA_01_P3 & $23 \%$ & $75 \%$ & $2 \%$ \\
\hline CA_PLA_01_P4 & 4,196 & 30,433 & 51,969 & 13,028 & 0,327 & 1,148 & 101,101 & _CA_PLA_01_P4 & $24 \%$ & $74 \%$ & $2 \%$ \\
\hline CA_PLA_01_P5 & 4,342 & 30,173 & 52,494 & 12,678 & 0,272 & 1,006 & 100,965 & _CA_PLA_01_P5 & $25 \%$ & $73 \%$ & $2 \%$ \\
\hline CA_PLA_01_P6 & 4,224 & 30,059 & 52,518 & 12,66 & 0,372 & 0,941 & 100,774 & CA_PLA_01_P6 & $24 \%$ & $73 \%$ & $2 \%$ \\
\hline CA_PLA_01_P7 & 4,427 & 30,161 & 52,548 & 12,361 & 0,326 & 1,054 & 100,877 & _CA_PLA_01_P7 & $26 \%$ & $72 \%$ & $2 \%$ \\
\hline CA_PLA_01_P8 & 5,573 & 28,747 & 54,509 & 10,659 & 0,39 & 0,964 & 100,842 & _CA_PLA_01_P8 & $34 \%$ & $64 \%$ & $2 \%$ \\
\hline CA_PLA_01_P9 & 4,337 & 30,701 & 51,217 & 12,844 & 0,599 & 1,424 & 101,122 & _CA_PLA_01_P9 & $24 \%$ & $72 \%$ & $3 \%$ \\
\hline CA_PLA_01_P10 & 5,363 & 28,636 & 54,569 & 10,851 & 0,952 & 1,095 & 101,466 & _CA_PLA_01_P10 & $31 \%$ & $63 \%$ & $6 \%$ \\
\hline CA_PLA_02_P1 & 4,24 & 30,369 & 52,065 & 12,73 & 0,403 & 1,336 & 101,143 & _CA_PLA_02_P1 & $24 \%$ & $73 \%$ & $2 \%$ \\
\hline CA_PLA_02_P2 & 4,84 & 29,894 & 52,656 & 12,009 & 0,322 & 0,9 & 100,621 & CA_PLA_02_P2 & $28 \%$ & $70 \%$ & $2 \%$ \\
\hline CA_PLA_02_P3 & 4,42 & 30,207 & 52,137 & 12,626 & 0,342 & 1,096 & 100,828 & CA_PLA_02_P3 & $25 \%$ & $73 \%$ & $2 \%$ \\
\hline
\end{tabular}


Tabela 2 - Resultados da análise química do plagioclásio utilizando microssonda eletrônica (continuação).

\begin{tabular}{|c|c|c|c|c|c|c|c|c|c|c|c|}
\hline Number & $\mathrm{Na}_{2} \mathrm{O}$ & $\mathrm{Al}_{2} \mathrm{O}_{3}$ & $\mathrm{SiO}_{2}$ & $\mathrm{CaO}$ & $\mathrm{K}_{2} \mathrm{O}$ & $\mathrm{FeO}$ & Total & Coluna1 & $\%$ Alb & $\%$ Arn & $\%$ Ort \\
\hline CA_PLA_02_P4 & 4,254 & 30,288 & 52,314 & 12,595 & 0,249 & 0,933 & 100,633 & _CA_PLA_02_P4 & $25 \%$ & $74 \%$ & $1 \%$ \\
\hline CA_PLA_02_P5 & 4,538 & 29,906 & 52,547 & 12,129 & 0,291 & 1,181 & 100,592 & _CA_PLA_02_P5 & $27 \%$ & $72 \%$ & $2 \%$ \\
\hline CA_PLA_02_P6 & 3,963 & 30,994 & 51,072 & 13,466 & 0,293 & 1,231 & 101,019 & _CA_PLA_02_P6 & $22 \%$ & $76 \%$ & $2 \%$ \\
\hline CB_PLA_01_P1 & 4,169 & 30,942 & 51,556 & 13,181 & 0,485 & 1,174 & 101,507 & _CB_PLA_01_P1 & $23 \%$ & $74 \%$ & $3 \%$ \\
\hline CB_PLA_01_P2 & 4,638 & 29,901 & 52,75 & 12,41 & 0,308 & 1,101 & 101,108 & _CB_PLA_01_P2 & $27 \%$ & $72 \%$ & $2 \%$ \\
\hline CB_PLA_01_P3 & 1,911 & 34,282 & 46,784 & 17,066 & 0,087 & 1,127 & 101,257 & _CB_PLA_01_P3 & $10 \%$ & $90 \%$ & $0 \%$ \\
\hline CB_PLA_01_P4 & 2,018 & 34,018 & 47,296 & 16,666 & 0,092 & 0,953 & 101,043 & _CB_PLA_01_P4 & $11 \%$ & $89 \%$ & $0 \%$ \\
\hline CB_PLA_01_P5 & 1,842 & 34,086 & 46,802 & 16,894 & 0,065 & 0,95 & 100,639 & _CB_PLA_01_P5 & $10 \%$ & $90 \%$ & $0 \%$ \\
\hline CB_PLA_01_P6 & 4,817 & 29,773 & 53,084 & 11,934 & 0,276 & 0,946 & 100,83 & _CB_PLA_01_P6 & $28 \%$ & $70 \%$ & $2 \%$ \\
\hline CB_PLA_01_P7 & 4,274 & 30,852 & 50,758 & 12,994 & 0,236 & 1,037 & 100,151 & _CB_PLA_01_P7 & $24 \%$ & $74 \%$ & $1 \%$ \\
\hline CB_PLA_01_P8 & 4,269 & 30,593 & 52,05 & 13,164 & 0,281 & 1,151 & 101,508 & _CB_PLA_01_P8 & $24 \%$ & $74 \%$ & $2 \%$ \\
\hline CD_PLA_01_B & 3,91 & 30,959 & 50,547 & 13,329 & 0,294 & 1,073 & 100,112 & _CD_PLA_01_B & $22 \%$ & $76 \%$ & $2 \%$ \\
\hline CD_PLA_01_N & 2,894 & 32,56 & 48,753 & 14,951 & 0,112 & 0,965 & 100,235 & _CD_PLA_01_N & $16 \%$ & $83 \%$ & $1 \%$ \\
\hline CE_PLA_01_P1 & 4,763 & 29,63 & 52,882 & 11,869 & 0,468 & 1,452 & 101,064 & _CE_PLA_01_P1 & $28 \%$ & $69 \%$ & $3 \%$ \\
\hline CE_PLA_01_P2 & 2,842 & 32,445 & 48,767 & 15,005 & 0,146 & 1,312 & 100,517 & _CE_PLA_01_P2 & $16 \%$ & $83 \%$ & $1 \%$ \\
\hline CE_PLA_01_P3 & 3,091 & 32,152 & 49,348 & 14,717 & 0,131 & 1,093 & 100,532 & _CE_PLA_01_P3 & $17 \%$ & $82 \%$ & $1 \%$ \\
\hline CE_PLA_01_P4 & 3,155 & 32,181 & 49,417 & 14,901 & 0,126 & 1,121 & 100,901 & _CE_PLA_01_P4 & $17 \%$ & $82 \%$ & $1 \%$ \\
\hline CE_PLA_01_P5 & 3,247 & 2,11 & 9,05 & 14,804 & 0,15 & 1,031 & 100,392 & _CE_PLA_01_P5 & $18 \%$ & $81 \%$ & $1 \%$ \\
\hline CE_PLA_01_P6 & 3,12 & 31,94 & 49,557 & 14,802 & 0,13 & 1 & 100,549 & _CE_PLA_01_P6 & $17 \%$ & $82 \%$ & $1 \%$ \\
\hline CE_PLA_01_P7 & 2,942 & 32,498 & 8,81 & 15,269 & 0,114 & 1,224 & 100,857 & _CE_PLA_01_P7 & $16 \%$ & $83 \%$ & $1 \%$ \\
\hline CE_PLA_02_B & 4,756 & 29,814 & 53,257 & 11,935 & 0,313 & 1,1 & 101,175 & _CE_PLA_02_B & $28 \%$ & $70 \%$ & $2 \%$ \\
\hline CE_PLA_02_N & 4,392 & 30,479 & 52,042 & 12,667 & 0,228 & 1,037 & 100,845 & _CE_PLA_02_N & $25 \%$ & $73 \%$ & $1 \%$ \\
\hline CA_PLA_01_P1 & 3,566 & 30,939 & 50,941 & 13,915 & 0,478 & 1,243 & 101,082 & _CA_PLA_01_P1 & $20 \%$ & $77 \%$ & $3 \%$ \\
\hline CA_PLA_01_P2 & 2,163 & 33,436 & 47,563 & 16,384 & 0,168 & 0,94 & 100,654 & _CA_PLA_01_P2 & $12 \%$ & $88 \%$ & $1 \%$ \\
\hline CA_PLA_ & 1,906 & 2,405 & 47,259 & 6,502 & 0,215 & 1,037 & 99,324 & CA_PL & $10 \%$ & $89 \%$ & $1 \%$ \\
\hline CA_PLA_01_P4 & 3,508 & 30,336 & 50,865 & 13,709 & 0,29 & 1,279 & 99,987 & _CA_PLA_01_P4 & $20 \%$ & $78 \%$ & $2 \%$ \\
\hline CA_PLA_01_P5 & 3,68 & 30,883 & 50,748 & 13,811 & 0,281 & 0,899 & 100,302 & CA_PLA_01_P5 & $21 \%$ & $78 \%$ & $2 \%$ \\
\hline CA_PLA_01_P6 & 3,392 & 31,007 & 50,614 & 14,056 & 0,278 & 0,971 & 100,318 & CA_PLA_01_P6 & $19 \%$ & $79 \%$ & $2 \%$ \\
\hline CA_PLA_01_P7 & 3,475 & 31,419 & 50,379 & 14,318 & 0,274 & 1,055 & 100,92 & _CA_PLA_01_P7 & $19 \%$ & $79 \%$ & $2 \%$ \\
\hline CA_PLA & 4,36 & 30,659 & 50,506 & 12,835 & 0,596 & 1,329 & 100,285 & 88 & $25 \%$ & $2 \%$ & $3 \%$ \\
\hline CD_PLA_INF_P1 & 4,157 & 30,213 & 51,458 & 13,085 & 0,576 & 1,463 & 100,952 & _CD_PLA_INF_P1 & $23 \%$ & $73 \%$ & $3 \%$ \\
\hline CD_PLA_INF_P2 & 3,348 & 31,333 & 50,165 & 14,267 & 0,325 & 1,097 & 100,535 & CD_PLA_INF_P2 & $19 \%$ & $80 \%$ & $2 \%$ \\
\hline CD_PLA_INF_P3 & 3,441 & 31,439 & 50,055 & 14,569 & 0,356 & 0,988 & 100,848 & _CD_PLA_INF_P3 & $19 \%$ & $79 \%$ & $2 \%$ \\
\hline CD_PLA_INF_P4 & 3,723 & 30,618 & 51,208 & 13,632 & 0,277 & 0,916 & 100,374 & CD_PLA_INF_P4 & $21 \%$ & $77 \%$ & $2 \%$ \\
\hline CD_PLA_INF_P5 & 2,359 & 33,077 & 47,641 & 16,115 & 0,157 & 0,945 & 100,294 & CD_PLA_INF_P5 & $13 \%$ & $86 \%$ & $1 \%$ \\
\hline CD_PLA_INF_P6 & 3,779 & 30,02 & 50,18 & 13,304 & 0,445 & 2,11 & 99,838 & _CD_PLA_INF_P6 & $22 \%$ & $76 \%$ & $3 \%$ \\
\hline CD_PLA_ & 2,489 & 32,732 & 48,104 & 15,753 & 0,215 & 1,012 & 100,305 & _CD_PLA_INF_P7 & $13 \%$ & $85 \%$ & $1 \%$ \\
\hline CD_PLA_INF_P8 & 2,929 & 31,633 & 49,111 & 14,555 & 0,397 & 1,589 & 100,214 & _CD_PLA_INF_P8 & $16 \%$ & $81 \%$ & $2 \%$ \\
\hline CD_PLA_MEIO_P1 & 4,829 & 29,091 & 52,98 & 11,797 & 0,867 & 1,298 & 100,862 & _CD_PLA_MEIO_P1 & $28 \%$ & $67 \%$ & $5 \%$ \\
\hline CD_PLA_MEIO_P2 & 3,666 & 0,94 & 50,804 & 13,745 & 0,268 & 0,822 & 100,245 & _CD_PLA_MEIO_P2 & $21 \%$ & $78 \%$ & $2 \%$ \\
\hline CD_PLA_MEIO_P3 & 2,312 & 32,948 & 48,044 & 15,826 & 0,155 & 0,937 & 100,222 & _CD_PLA_MEIO_P3 & $13 \%$ & $87 \%$ & $1 \%$ \\
\hline CD_PLA_MEIO_P4 & 2,974 & 31,899 & 49,112 & 14,917 & 0,188 & 0,84 & 99,93 & _CD_PLA_MEIO_P4 & $16 \%$ & $83 \%$ & $1 \%$ \\
\hline CD_PLA_MEIO_P5 & 2,332 & 33,133 & 47,753 & 16,156 & 0,141 & 0,806 & 100,321 & _CD_PLA_MEIO_P5 & $13 \%$ & $87 \%$ & $1 \%$ \\
\hline CD_PLA_MEIO_P6 & 2,374 & 33,138 & 47,888 & 16,03 & 0,153 & 0,83 & 100,413 & _CD_PLA_MEIO_P6 & $13 \%$ & $86 \%$ & $1 \%$ \\
\hline CD_PLA_MEIO_P7 & 2,375 & 32,873 & 47,918 & 16,078 & 0,151 & 0,95 & 100,345 & _CD_PLA_MEIO_P7 & $13 \%$ & $86 \%$ & $1 \%$ \\
\hline
\end{tabular}

São Paulo, UNESP, Geociências, v. 39, n. 2, p. 343 - 359, 2020 
Tabela 2 - Resultados da análise química do plagioclásio utilizando microssonda eletrônica (continuação).

\begin{tabular}{|c|c|c|c|c|c|c|c|c|c|c|c|}
\hline Number & $\mathrm{Na}_{2} \mathrm{O}$ & $\mathrm{Al}_{2} \mathrm{O}_{3}$ & $\mathrm{SiO}_{2}$ & $\mathrm{CaO}$ & $\mathrm{K}_{2} \mathrm{O}$ & $\mathrm{FeO}$ & Total & Coluna1 & $\%$ Alb & $\%$ Arn & $\%$ Ort \\
\hline CD_PLA_MEIO_P8 & 4,188 & 30,426 & 51,484 & 12,932 & 0,502 & 1,188 & 100,72 & _CD_PLA_MEIO_P8 & $24 \%$ & $73 \%$ & $3 \%$ \\
\hline CD_PLA_SUP_P1 & 3,896 & 30,431 & 51,218 & 13,295 & 0,504 & 1,043 & 100,387 & CD_PLA_SUP_P1 & $22 \%$ & $75 \%$ & $3 \%$ \\
\hline CD_PLA_SUP_P2 & 4,507 & 29,677 & 52,294 & 12,364 & 0,328 & 0,974 & 100,144 & CD_PLA_SUP_P2 & $26 \%$ & $72 \%$ & $2 \%$ \\
\hline CD_PLA_SUP_P3 & 3,659 & 30,945 & 50,727 & 13,843 & 0,232 & 1,03 & 100,436 & _CD_PLA_SUP_P3 & $21 \%$ & $78 \%$ & $1 \%$ \\
\hline CD_PLA_SUP_P4 & 3,606 & 30,956 & 50,644 & 13,68 & 0,264 & 0,8 & 99,95 & CD_PLA_SUP_P4 & $21 \%$ & $78 \%$ & $2 \%$ \\
\hline CD_PLA_SUP_P5 & 2,541 & 33,029 & 47,827 & 15,962 & 0,136 & 0,93 & 100,425 & _CD_PLA_SUP_P5 & $14 \%$ & $86 \%$ & $1 \%$ \\
\hline CD_PLA_SUP_P6 & 3,864 & 30,58 & 51,164 & 13,43 & 0,276 & 1,027 & 100,341 & _CD_PLA_SUP_P6 & $22 \%$ & $76 \%$ & $2 \%$ \\
\hline CD_PLA_SUP_P7 & 3,664 & 30,939 & 50,67 & 13,909 & 0,27 & 0,915 & 100,367 & _CD_PLA_SUP_P7 & $21 \%$ & $78 \%$ & $2 \%$ \\
\hline CD_PLA_SUP_P8 & 3,698 & 30,704 & 50,862 & 13,25 & 0,448 & 1,124 & 100,086 & _CD_PLA_SUP_P8 & $21 \%$ & $76 \%$ & $3 \%$ \\
\hline CD_PLA_SUP_P9 & 4,206 & 29,967 & 51,868 & 12,987 & 0,449 & 1,063 & 100,54 & _CD_PLA_SUP_P9 & $24 \%$ & $74 \%$ & $3 \%$ \\
\hline CE_PLA_01_P1 & 3,035 & 24,281 & 43,294 & 7,971 & 0,572 & 19,748 & 98,901 & _CE_PLA_01_P1 & $26 \%$ & $69 \%$ & $5 \%$ \\
\hline CE_PLA_01_P2 & 4,142 & 30,261 & 51,408 & 13,151 & 0,56 & 1,08 & 100,602 & _CE_PLA_01_P2 & $23 \%$ & $74 \%$ & $3 \%$ \\
\hline CE_PLA_01_P3 & 4,984 & 29,133 & 53,312 & 11,216 & 0,653 & 1,238 & 100,536 & _CE_PLA_01_P3 & $30 \%$ & $67 \%$ & $4 \%$ \\
\hline CE_PLA_01_P4 & 4,049 & 30,459 & 51,098 & 13,48 & 0,374 & 1,158 & 100,618 & CE_PLA_01_P4 & $23 \%$ & $75 \%$ & $2 \%$ \\
\hline CE_PLA_01_P5 & 3,786 & 30,663 & 51,178 & 13,724 & 0,299 & 1,084 & 100,734 & CE_PLA_01_P5 & $21 \%$ & $77 \%$ & $2 \%$ \\
\hline CE_PLA_01_P6 & 4,095 & 30,14 & 51,58 & 13,142 & 0,348 & 0,983 & 100,288 & _CE_PLA_01_P6 & $23 \%$ & $75 \%$ & $2 \%$ \\
\hline CE_PLA_01_P7 & 4,036 & 30,415 & 51,586 & 13,333 & 0,314 & 1,048 & 100,732 & _CE_PLA_01_P7 & $23 \%$ & $75 \%$ & $2 \%$ \\
\hline CE_PLA_01_P8 & 3,979 & 30,332 & 51,343 & 13,246 & 0,438 & 1,069 & 100,407 & _CE_PLA_01_P8 & $23 \%$ & $75 \%$ & $2 \%$ \\
\hline CE_PLA_01_P9 & 4,208 & 29,788 & 52,244 & 12,881 & 0,533 & 1,328 & 100,982 & _CE_PLA_01_P9 & $24 \%$ & $73 \%$ & $3 \%$ \\
\hline CF_PLA_01_P1 & 3,385 & 31,597 & 49,66 & 14,553 & 0,266 & 1,027 & 100,488 & CF_PLA_01_P1 & $19 \%$ & $80 \%$ & $1 \%$ \\
\hline CF_PLA_01_P2 & 3,963 & 30,218 & 51,431 & 13,402 & 0,31 & 0,954 & 100,278 & _CF_PLA_01_P2 & $22 \%$ & $76 \%$ & $2 \%$ \\
\hline CF_PLA_01_P3 & 3,886 & 30,352 & 51,268 & 13,383 & 0,252 & 0,94 & 100,081 & _CF_PLA_01_P3 & $22 \%$ & $76 \%$ & $1 \%$ \\
\hline CF_PLA_01_P4 & 4,119 & 30,303 & 51,75 & 13,184 & 0,26 & 0,941 & 100,557 & _CF_PLA_01_P4 & $23 \%$ & $75 \%$ & $1 \%$ \\
\hline CF_PLA_01_P5 & 3,811 & 30,956 & 50,754 & 13,776 & 0,258 & 0,962 & 100,517 & _CF_PLA_01_P5 & $21 \%$ & $77 \%$ & $1 \%$ \\
\hline CF_PLA_01_P6 & 3,311 & 31,383 & 49,858 & 14,425 & 0,169 & 0,926 & 100,072 & _CF_PLA_01_P6 & $18 \%$ & $81 \%$ & $1 \%$ \\
\hline CF_PLA_01_P7 & 3,541 & 30,993 & 50,473 & 13,83 & 0,193 & 0,967 & 99,997 & _CF_PLA_01_P7 & $20 \%$ & $79 \%$ & $1 \%$ \\
\hline CF_PLA_01_P8 & 4,186 & 30,13 & 51,955 & 12,928 & 0,548 & 1,27 & 101,017 & _CF_PLA_01_P8 & $24 \%$ & $73 \%$ & $3 \%$ \\
\hline CF_PLA_02_B1 & 3,579 & 30,847 & 49,628 & 13,863 & 0,485 & 0,985 & 99,387 & CF_PLA_02_B1 & $20 \%$ & $77 \%$ & $3 \%$ \\
\hline CF_PLA_02_B2 & 3,505 & 31,399 & 50,286 & 14,351 & 0,344 & 1,069 & 100,954 & _CF_PLA_02_B2 & $19 \%$ & $79 \%$ & $2 \%$ \\
\hline CF_PLA_02_N & 3,644 & 31,12 & 50,289 & 14,076 & 0,262 & 0,951 & 100,342 & _CF_PLA_02_N & $20 \%$ & $78 \%$ & $1 \%$ \\
\hline CF_PLA_03_B1 & 3,646 & 31,255 & 50,681 & 14,08 & 0,298 & 1,05 & 101,01 & _CF_PLA_03_B1 & $20 \%$ & $78 \%$ & $2 \%$ \\
\hline CF_PLA_03_B2 & 3,45 & 31,629 & 49,927 & 14,317 & 0,338 & 1,059 & 100,72 & _CF_PLA_03_B2 & $19 \%$ & $79 \%$ & $2 \%$ \\
\hline CF_PLA_03_N & 3,338 & 31,84 & 49,572 & 14,488 & 0,209 & 0,872 & 100,319 & _CF_PLA_03_N & $19 \%$ & $80 \%$ & $1 \%$ \\
\hline
\end{tabular}

\section{Piroxênio}

Segundo o diagrama de classificação de Deer (1992), os cristais de piroxênio analisados são classificados como augita/ ferroaugita (Figura 5). Apresentam zoneamento composi-cional inverso, com aumento nos teores de $\mathrm{Ca}$ e $\mathrm{Mg}$ e diminuição nos teores de Fe do núcleo para a borda.

\section{Plagioclásio}

Para os fenocristais que apresentaram zoneamento composicional no estudo petrográfico, foram realizadas análises de perfil e nos grãos aparentemente homogêneos foram realizadas análises de núcleo e borda. Os resultados analíticos indicam que $o$ plagioclásio possui uma composição cálcica, com teores menores de sódio e baixos níveis de potássio. Os pontos analisados se classificam predominantemente dentro do campo da bytownita $\left(\mathrm{An}_{70-90}\right)$ no diagrama de classificação química de Deer (1992). Localizadamente, há também pontos classificados como labradorita, conforme indicado na Figura 6. 


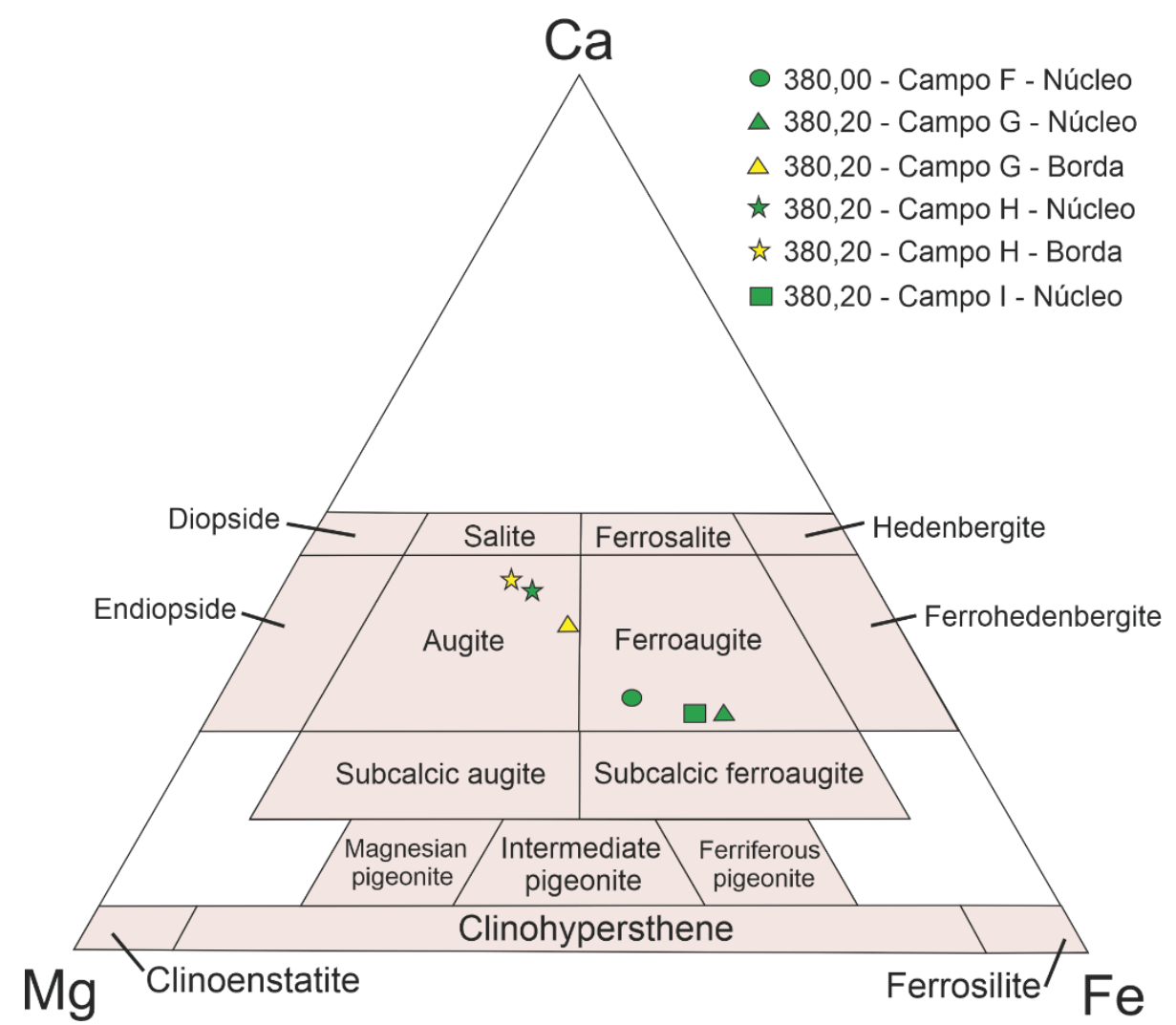

Figura 5 - Diagrama de classificação química do piroxênio (Deer, 1992).

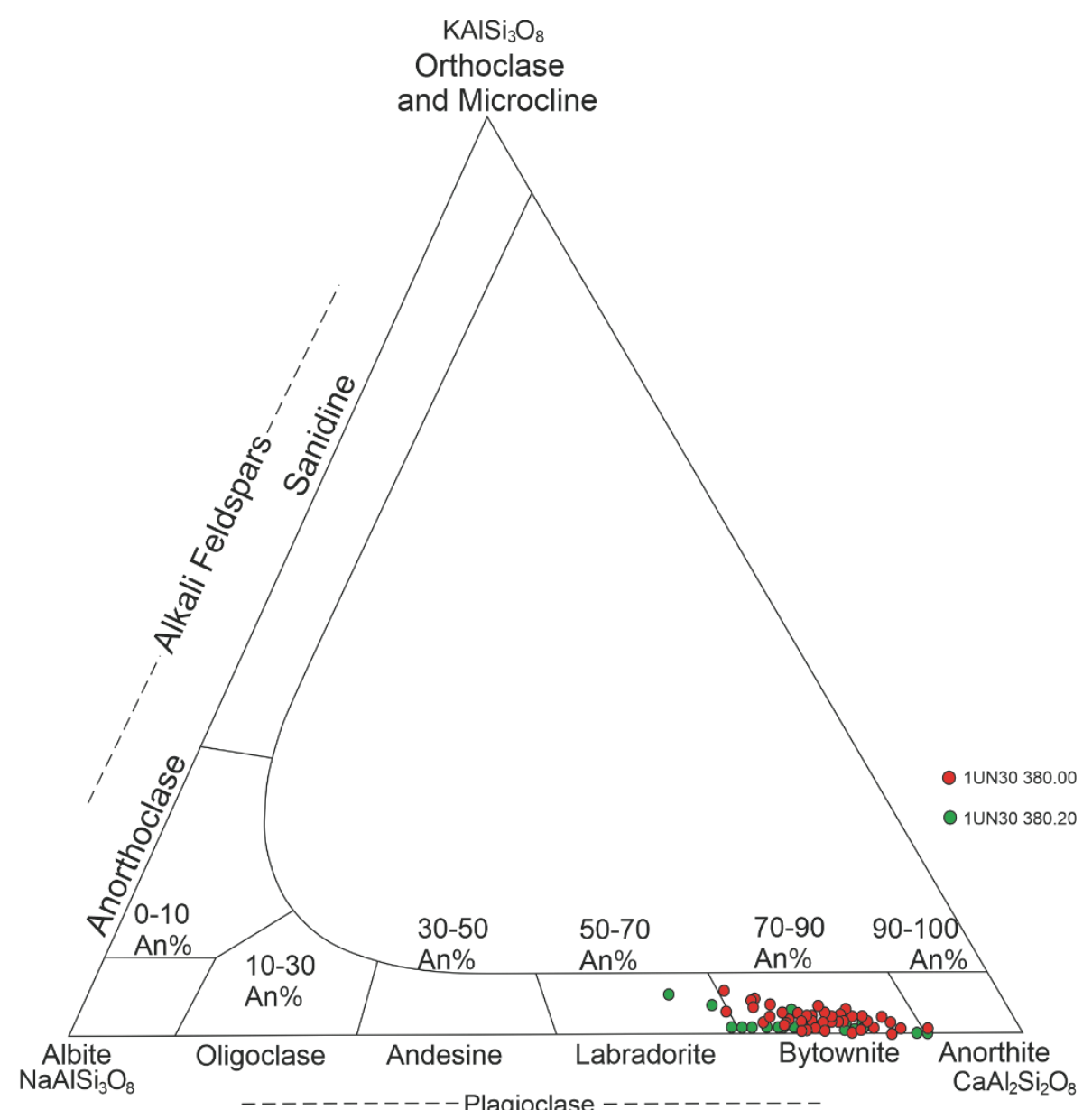

Figura 6 - Diagrama de classificação química do feldspato (Deer, 1992).

Os gráficos de variação dos teores de $\mathrm{Ca}, \mathrm{Na}$ e apresenta zoneamento composicional normal, onde $\mathrm{K}$ e a ilustração dos pontos analisados estão o núcleo dos cristais possui composição mais dispostos na figura 7 . Verifica-se que o plagioclásio enriquecida em cálcio que a borda. 


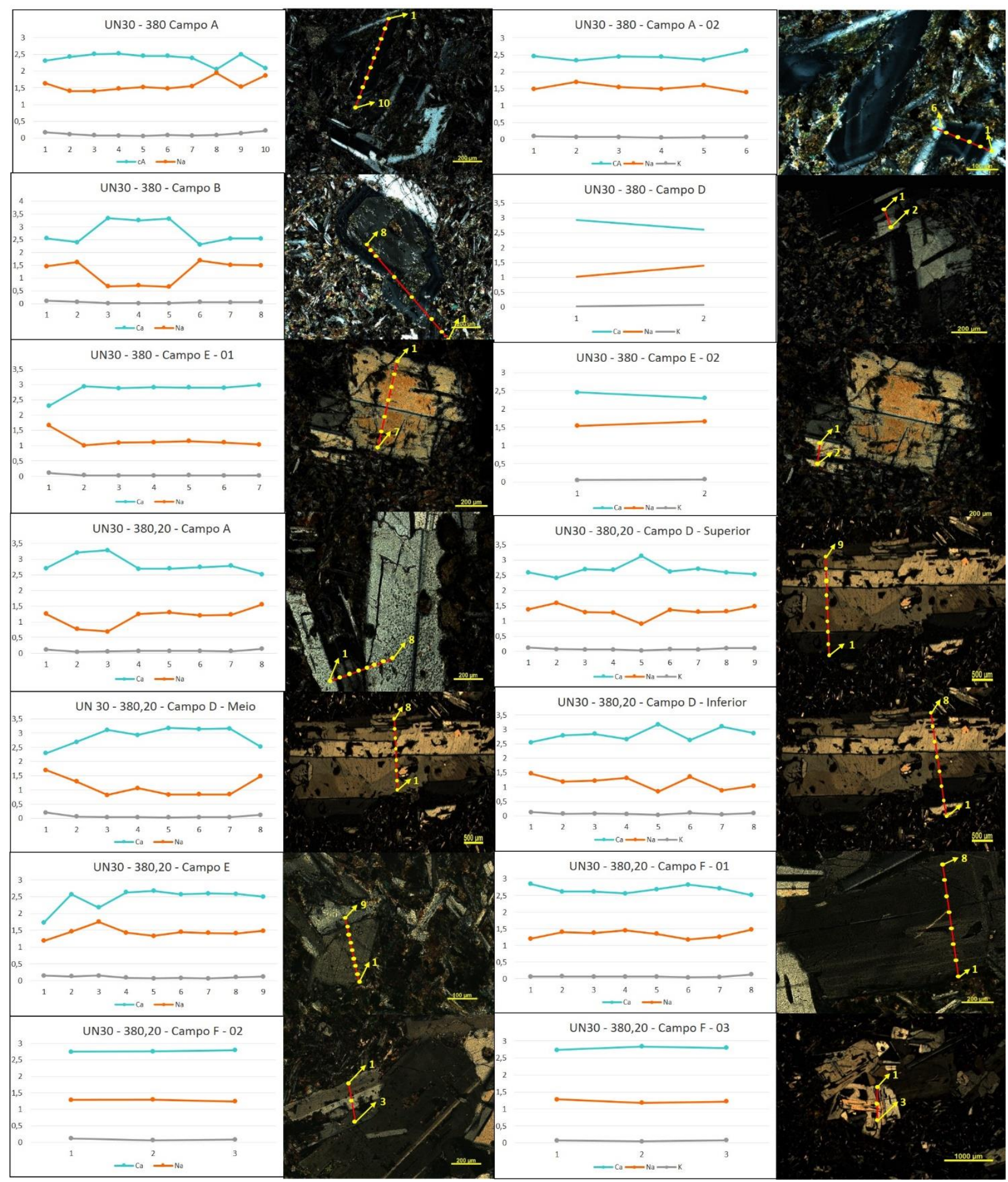

Figura 7 - Gráficos de variação dos níveis de Ca, Na e K ao longo de uma seção de pontos amostrados em plagioclásios zonados.

A análise desses gráficos também permite identificar duas diferentes fases de formação de fenocristais de plagioclásio ao longo da evolução magmática dessa intrusão. A fase de cristalização mais recente possui níveis médios de $2,5 \%$ de cálcio, podendo alcançar até $3 \%$ de sua composição química total. Ela consiste principalmente em fenocristais isolados homogêneos ou zonados e que, eventualmente, apresentam textura em peneira fina.
Localmente, os fenocristais desta fase também apresentam syneuses. Estas possuem uma composição química ainda menos cálcica (geralmente em torno de 2,5\%) o que indica que se formaram posteriormente aos fenocristais aos quais são subordinadas. Além disso, esta fase de cristalização mais nova também é encontrada em associação com a fase anterior, consistindo neste caso as bordas dos núcleos corroídos. 
A fase mais antiga tem níveis de cálcio próximos a 3,5\% de sua composição química total e aparece unicamente em associação com a fase posterior de cristalização, apresentando-se como núcleo de alguns fenocristais de plagioclásio. Em alguns grãos o núcleo (mais cálcico) encontra-se corroído e apresenta textura em peneira grossa e zoneamento enquanto a borda está apenas zonada e localmente com textura em peneira fina.

Tais características foram observadas igualmente nas duas lâminas magmáticas, não havendo nenhuma mudança observada da composição do plagioclásio com a variação da profundidade.

\section{MEV-EDS}

Os resultados analíticos obtidos a partir das análises em MEV-EDS encontram-se listados na tabela 3. No total, foram analisados dezenove pontos nos elementos $\mathrm{O}, \mathrm{Si}, \mathrm{Al}, \mathrm{Mg}$, $\mathrm{Fe}, \mathrm{K}, \mathrm{Na}$ e $\mathrm{S}$.

Os resultados apontam que os interstícios da rocha sedimentar encaixante são preenchidos por argilominerais do grupo da esmectita, por cristais dos grupos da clorita e da zeólita, por grãos de anfibólio e por K-feldspato (Figura 8).
Os argilominerais são os minerais de preenchimento mais comuns. Tanto ele quanto os grãos dos grupos da clorita e da zeólita, estes últimos pouco frequentes, aparecem como minerais fibrosos nas bordas dos interstícios e em contato com os grãos do arcabouço. Os cristais de anfibólio são geralmente granulares e localizam-se na região central dos interstícios da rocha. Além disso, eles encontram-se fortemente alterados para minerais ricos em ferro e associados à alteração hidrotermal. O kfeldspato é a variedade mineral menos frequente encontrada, aparecendo localmente como cristais tabulares nas bordas dos interstícios.

Uma associação comum desse preenchimento é mostrada na Figura 9, onde foi feito um mapeamento dos elementos principais sobre a imagem de MEV. Observa-se uma região central rica em magnésio com uma borda rica em ferro e uma franja de cristais ricos em potássio. A região enriquecida em $\mathrm{Mg}$ e Fe constitui o cristal de anfibólio, com o núcleo preservado e as bordas alteradas. Os cristais de aparência fibrosa ricos em potássio nas bordas do interstício constituem cristais de ilita.

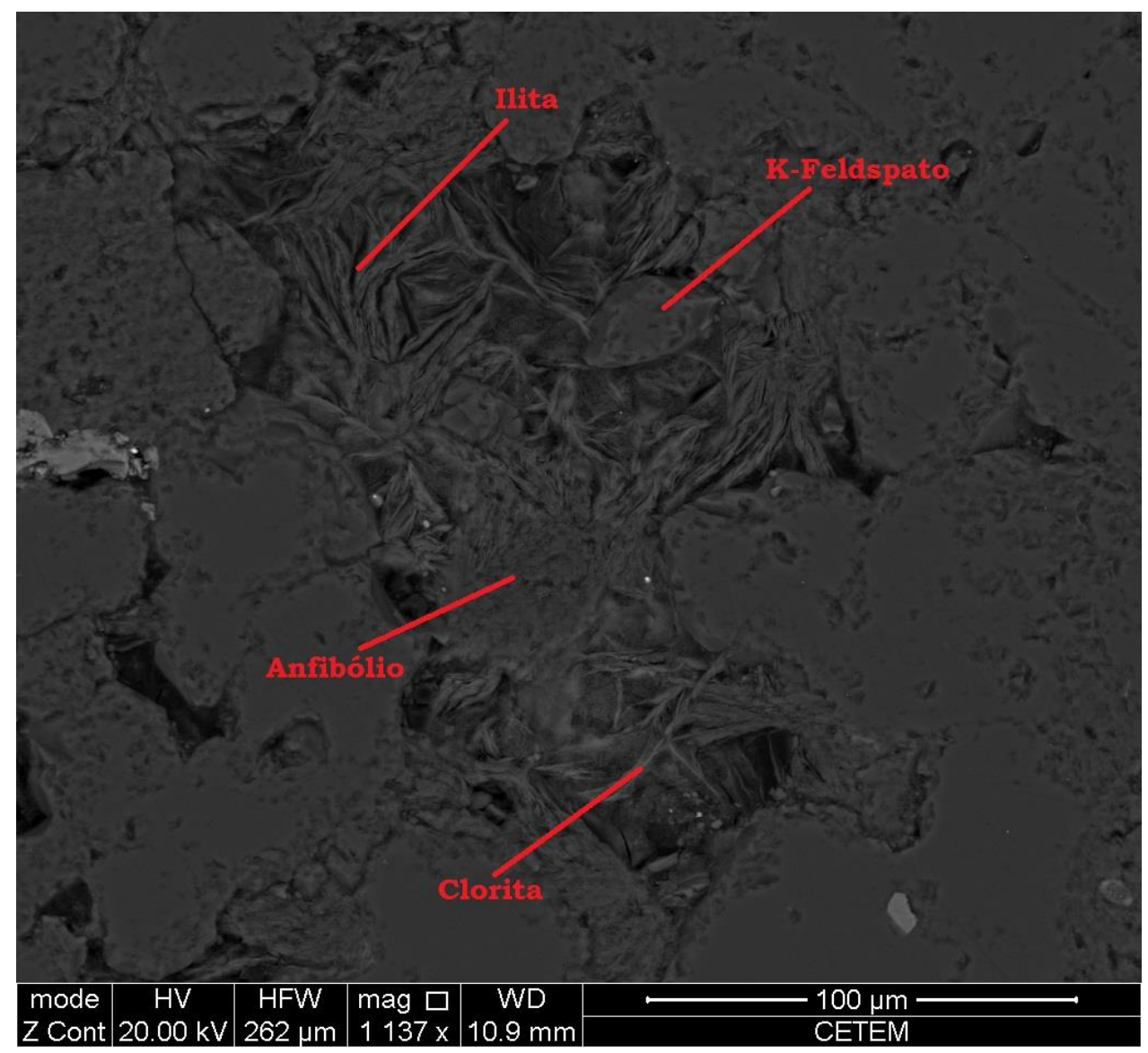

Figura 8 - Foto de imagem de MEV de interstício preenchido com ilita, clorita, K-feldspato e anfibólio. 


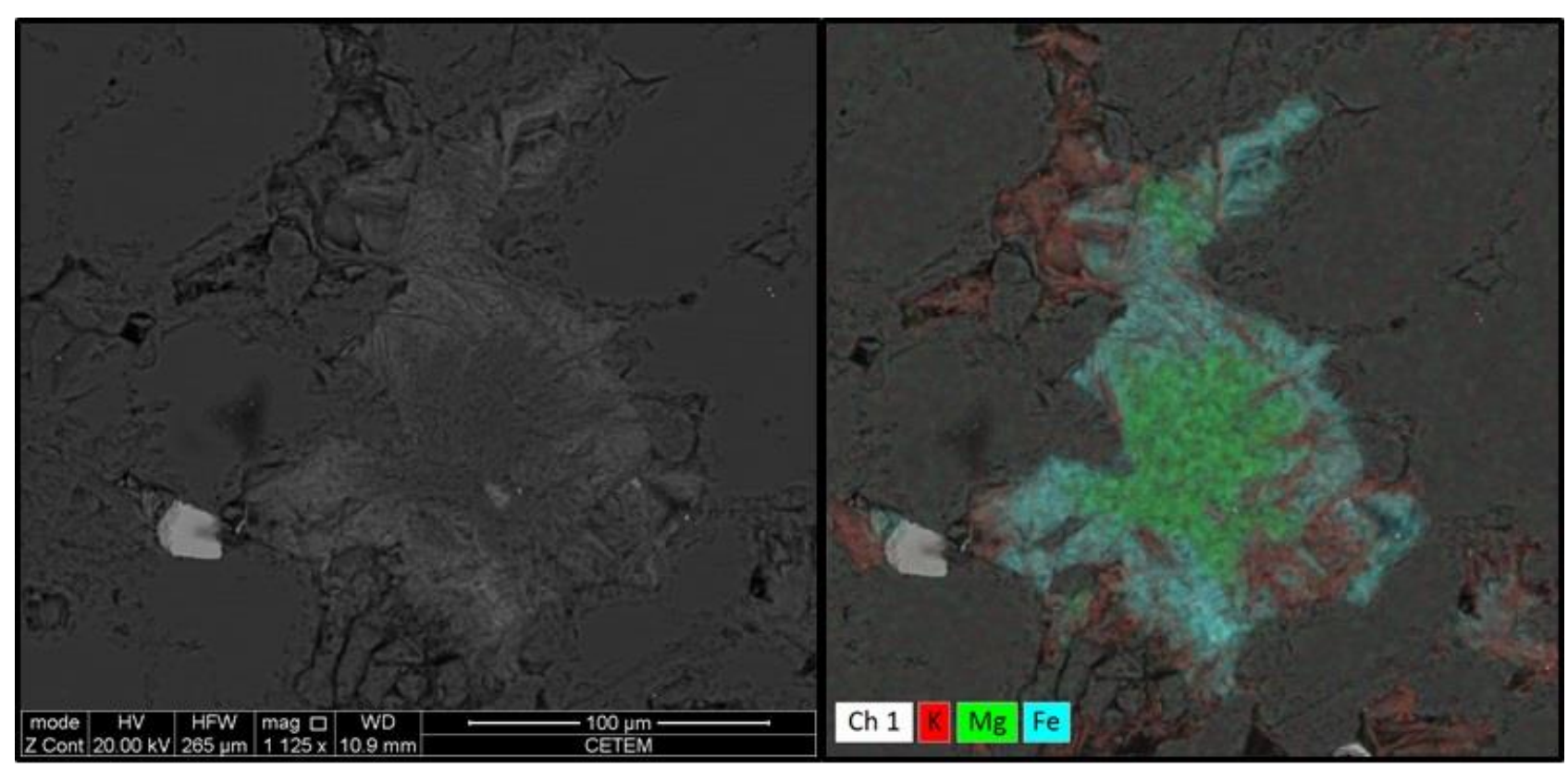

Figura 9 - Foto de imagem de MEV (esquerda) com o mapeamento dos elementos (direita).

Tabela 3 - Resultados das análises de MEV.

\begin{tabular}{c|c|c|c|c|c|c|c|c}
\hline Ponto & Oxigênio & Silício & Alumínio & Magnésio & Ferro & Potássio & Sódio & Enxofre \\
\hline $\mathbf{0 3}$ & 61,04 & 16,64 & 16,11 & 0,76 & 0,21 & 3,93 & 1,31 & - \\
\hline $\mathbf{0 5}$ & 58,51 & 10,67 & 12,70 & 10,43 & 7,68 & - & - & - \\
\hline $\mathbf{0 8}$ & 60,89 & 13,60 & 17,41 & 4,47 & 2,00 & 0,06 & 1,50 & 0,07 \\
\hline $\mathbf{1 0 a}$ & 55,68 & 19,12 & 18,84 & 0,44 & 0,23 & 3,61 & 1,94 & 0,13 \\
\hline $\mathbf{1 0 b}$ & 61,54 & 13,80 & 10,99 & 9,31 & 2,28 & 0,59 & 0,93 & 0,56 \\
\hline $\mathbf{1 1 a - K}$ & 60,34 & 18,62 & 15,89 & 0,13 & 0,41 & 2,44 & 1,98 & 0,18 \\
\hline $\mathbf{1 1 a - M g}$ & 60,16 & 11,76 & 11,00 & 14,67 & 2,16 & 0,08 & 0,04 & 0,13 \\
\hline $\mathbf{1 2 - F e}$ & 55,73 & 11,97 & 14,19 & 6,12 & 11,63 & 0,06 & 0,07 & 0,23 \\
\hline $\mathbf{1 2 - K}$ & 49,19 & 23,40 & 20,39 & 0,24 & 0,33 & 4,90 & 1,38 & 0,16 \\
\hline $\mathbf{1 2 - M g}$ & 59,50 & 11,70 & 11,59 & 14,39 & 2,74 & 0,02 & 0,01 & 0,05 \\
\hline $\mathbf{1 3 - F e}$ & 60,86 & 10,54 & 12,75 & 6,29 & 9,39 & 0,06 & 0,06 & 0,05 \\
\hline $\mathbf{1 3 - K}$ & 55,89 & 15,18 & 15,05 & 8,39 & 3,06 & 1,75 & 0,48 & 0,19 \\
\hline $\mathbf{1 3 - M g - M}$ & 58,96 & 11,81 & 11,73 & 14,61 & 2,75 & 0,02 & 0,01 & 0,09 \\
\hline $\mathbf{1 3 - M g - S}$ & 59,59 & 12,64 & 8,10 & 1,47 & 16,15 & 0,34 & 0,46 & 1,25 \\
\hline $\mathbf{1 4 - k}$ & 59,38 & 18,02 & 16,78 & 0,28 & 0,14 & 4,27 & 1,08 & 0,04 \\
\hline $\mathbf{1 4 - M g}$ & 59,13 & 10,79 & 12,14 & 9,16 & 7,97 & 0,24 & 0,24 & 0,33 \\
\hline $\mathbf{1 5 - F e}$ & 58,59 & 12,81 & 8,33 & 1,68 & 16,09 & 0,88 & 0,46 & 1,17 \\
\hline $\mathbf{1 5 - K}$ & 57,08 & 19,99 & 16,16 & 0,40 & 0,33 & 4,52 & 1,21 & 0,32 \\
\hline $\mathbf{1 5 - M g}$ & 59,53 & 11,58 & 11,67 & 13,95 & 3,05 & 0,06 & 0,05 & 0,11 \\
\hline
\end{tabular}

\section{Litogeoquímica}

Os resultados obtidos pela litogeoquímica, quando projetados nos diagramas AFM (Irvine \& Baragar, 1971; Figura 10) e TAS (Le Bas et. al., 1986, com curva de Irvine \& Baragar, 1971; Figura 11) classificam a rocha da intrusão como basalto da série toleítica. Esses basaltos são levemente empobrecidos em $\mathrm{MgO}$ (5,5 - 5,7\%), enriquecidos em FeOt $(15,0-17,2 \%)$ e com teores moderados de $\mathrm{TiO} 2(2,2 \%)$.

O gráfico discriminante de ambientes tectônicos (Pearce \& Norry, 1979; Figura 12) confirma que se tratam de basaltos intraplaca. 


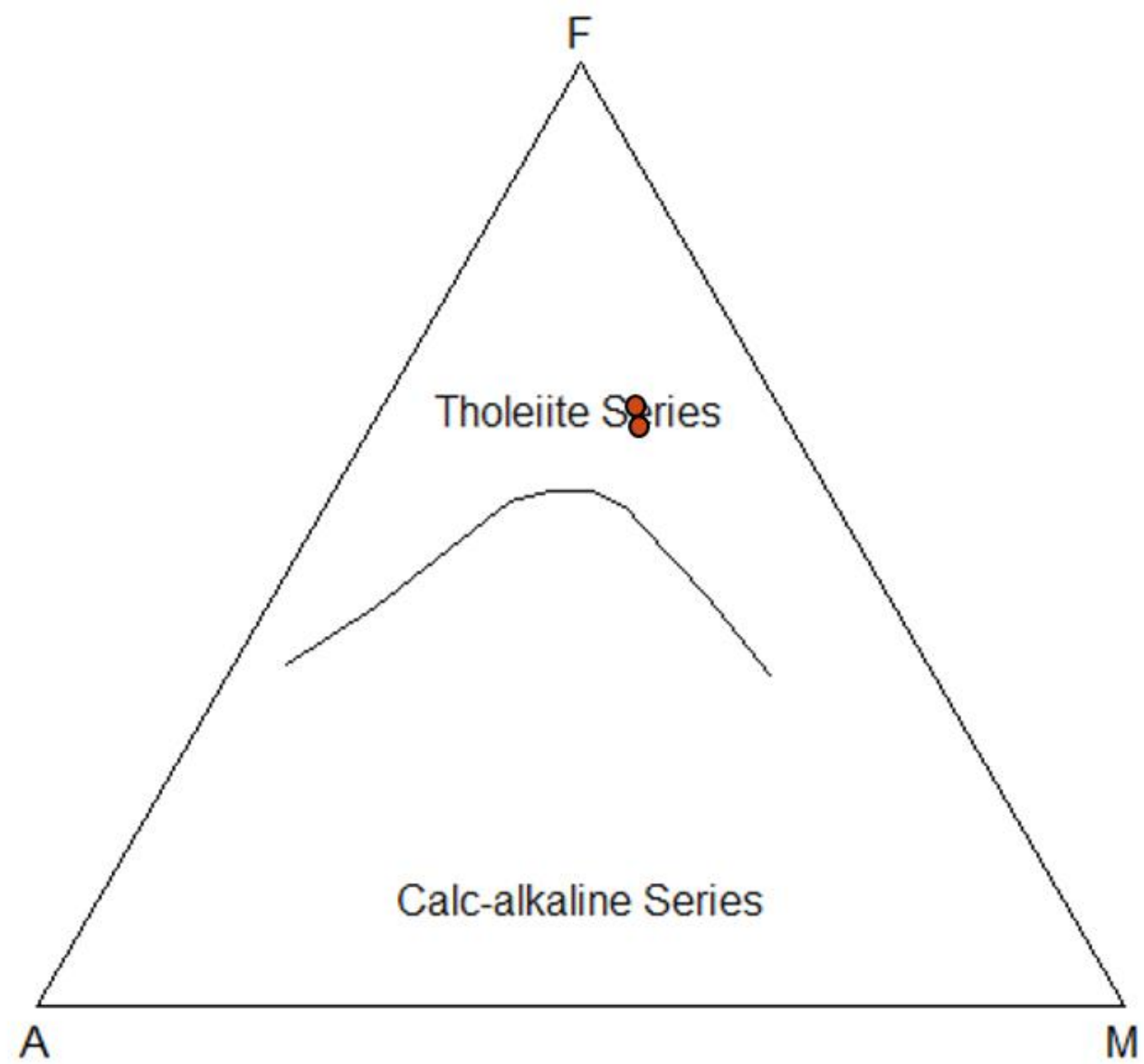

Figura 10 - Diagrama de classificação AFM (Irvine \& Baragar, 1971).

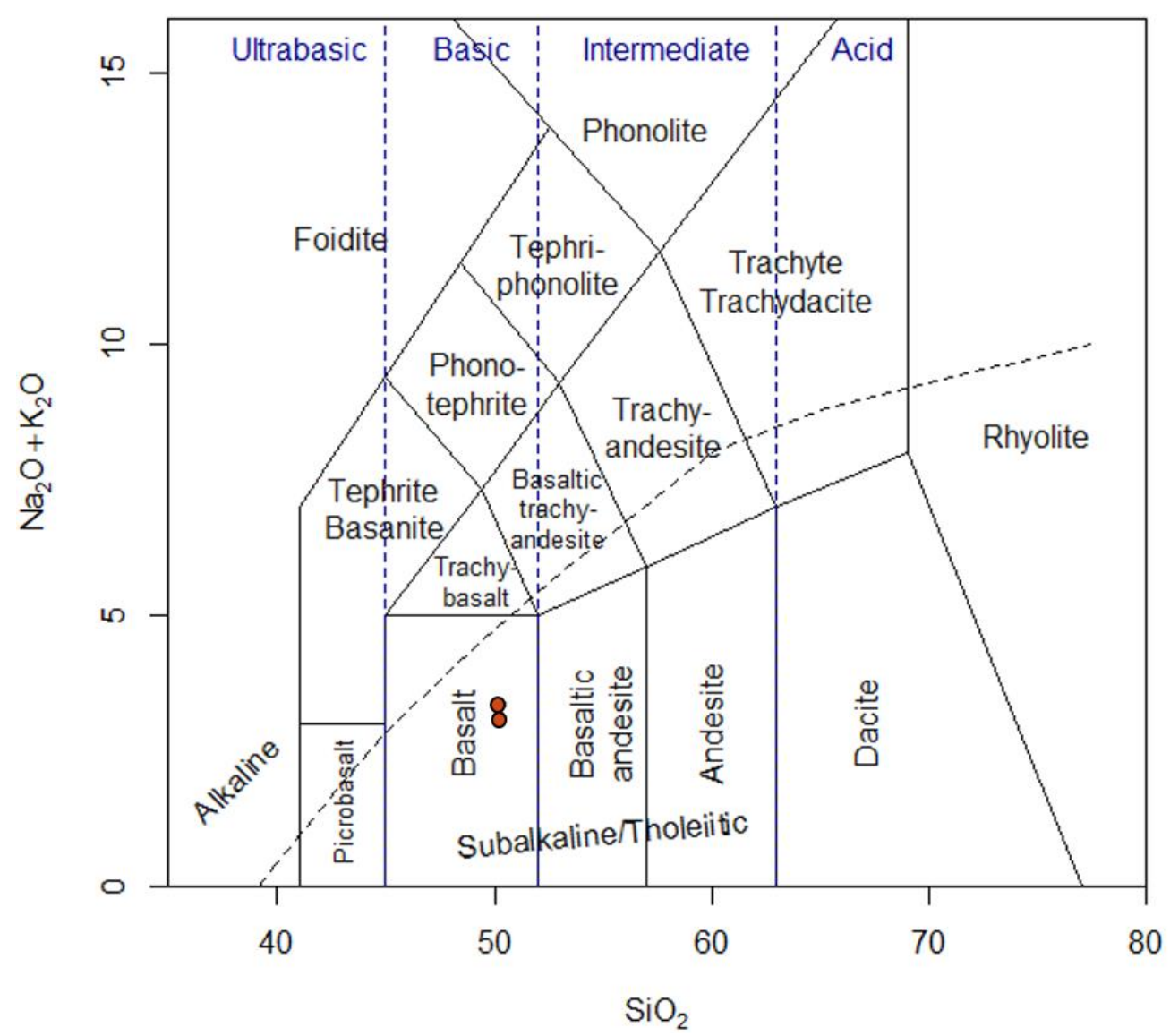

Figura 11 - Diagrama de classificação TAS (Le Bas et. al., 1986). 


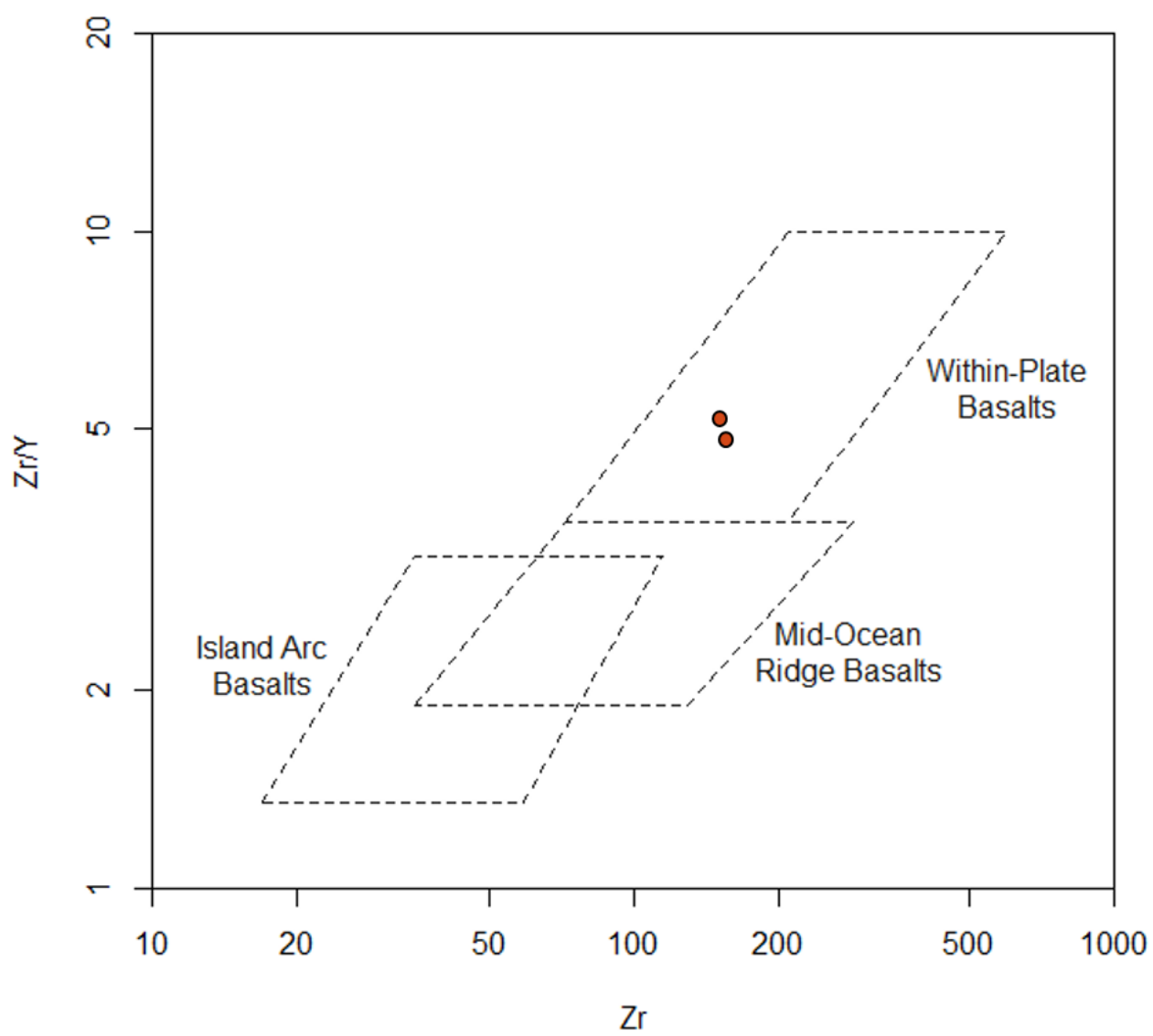

Figura 12 - Diagrama de classificação de ambiência geotectônica (Pearce \& Norry, 1979).

No diagrama multielementar normalizado para o manto primitivo (Mc Dounagh \& Sun, 1995; Figura 13) observa-se que as amostras apresentam enriquecimento geral no espectro de elementos-traço, embora verifique-se um maior enriquecimento dos LILE (20 a 40 vezes o manto primitivo) em relação aos HFSE ( 5 a 7 vezes o manto primitivo), e razões médias LILE $_{N} / \mathrm{HFSE}_{\mathrm{N}}$ entre 4,0 e 9,2. Depressões em $\mathrm{Nb}, \mathrm{Ta}$, Sr e P também foram constatadas. Os padrões observados são similares a padrões de basaltos de derrames continentais observados em vários continentes (eg. Thompson et al., 1983; Peate et al, 1992; Peate \& Hawkesworth, 1996; 2000; Beccaluva et al., 2009).

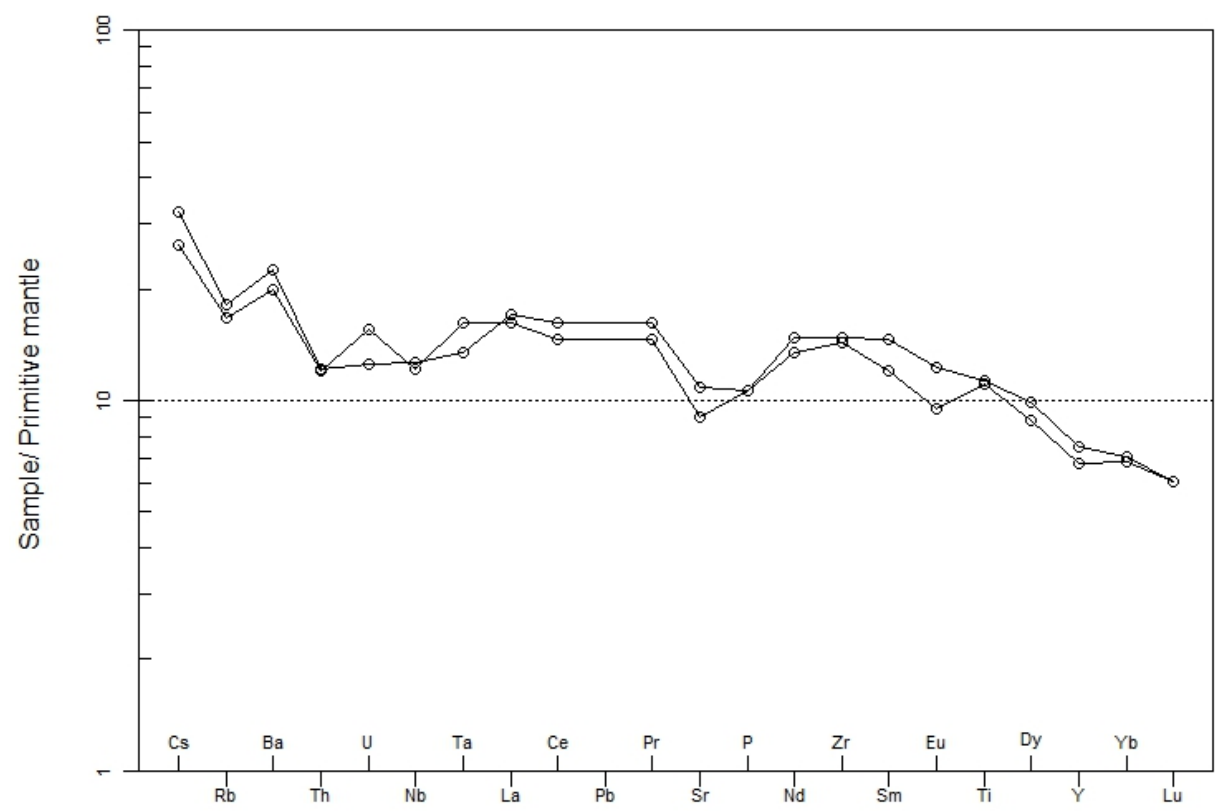

Figura 13 - Spidergram multielementar normalizado para o manto primitivo (Mc Dounagh \& Sun, 1995). 
No diagrama normalizado para elementos terras raras segundo o condrito de Boyton (1984; Figura 14) verifica-se também o enriquecimento em todos os elementos, muito embora apresentem-se levemente fracionados revelando um maior enriquecimento nos
ETRL em relação aos ETRP, com razão média $\mathrm{Ce}_{\mathrm{N}} / \mathrm{YB}_{\mathrm{N}}$ em torno de 4,0. Uma outra feição observada nesses padrões é uma moderada anomalia negativa de $\mathrm{Eu}$ que pode estar relacionada com as condições de fO2 e/ou fracionamento de plagioclásio.

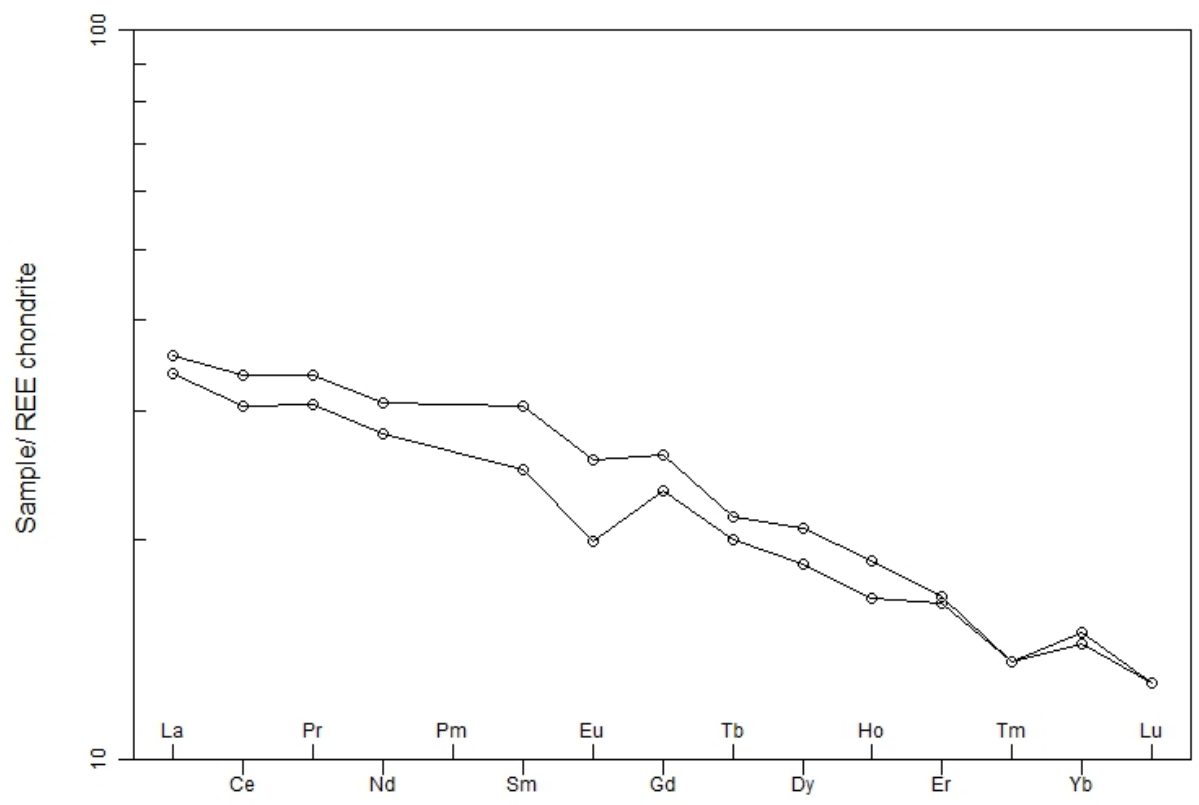

Figura 14 - Spidergram multielementar normalizado para o condrito (Boynton, 1984).

Tabela 4 - Resultados das análises litogeoquímicas.

Tabela 4 (parte 1)

\begin{tabular}{c|c|c|c|c|c|c|c|c|c|c|c|c|c|c|c}
\hline AMOSTRA & Ba & Ce & \multicolumn{1}{c|}{ Cr } & Cs & Dy & Er & Eu & Ga & Gd & Hf & Ho & La & Lu & Nb & Nd \\
\hline DESCRIPTION & ppm & ppm & ppm & ppm & ppm & ppm & ppm & ppm & ppm & ppm & ppm & ppm & ppm & ppm & ppm \\
\hline $\mathbf{1 U N - 3 0 ~ 3 8 0 , 2 0 ~}$ & 148,5 & 27,2 & 70 & 0,68 & 6,67 & 3,5 & 1,89 & 22,2 & 6,75 & 4,3 & 1,34 & 11,1 & 0,41 & 8,3 & 18,5 \\
\hline 1UN-30 380,00 & 131,5 & 24,6 & 70 & 0,55 & 5,95 & 3,43 & 1,46 & 24,2 & 6,05 & 4,3 & 1,19 & 10,5 & 0,41 & 8 & 16,8 \\
\hline
\end{tabular}

Tabela 4 (parte 2)

\begin{tabular}{c|c|c|c|c|c|c|c|c|c|c|c|c|c|c|c}
\hline AMOSTRA & Pr & Rb & Sm & Sn & Sr & Ta & Tb & Th & Tm & U & V & W & Y & Yb & Zr \\
\hline DESCRIPTION & ppm & ppm & ppm & ppm & ppm & ppm & ppm & ppm & ppm & ppm & ppm & ppm & ppm & ppm & ppm \\
\hline 1UN-30 380,20 & 4,11 & 10,9 & 5,94 & 2 & 216 & 0,5 & 1,02 & 0,97 & 0,44 & 0,25 & 494 & $<1$ & 32,3 & 3,11 & 155 \\
\hline 1UN-30 380,00 & 3,73 & 10 & 4,87 & 3 & 179 & 0,6 & 0,95 & 0,96 & 0,44 & 0,31 & 480 & 1 & 29,1 & 3,01 & 151 \\
\hline
\end{tabular}

Tabela 4 (parte 3)

\begin{tabular}{|c|c|c|c|c|c|c|c|c|c|c|c|c|c|c|c|}
\hline AMOSTRA & $\mathrm{SiO}_{2}$ & $\mathrm{Al}_{2} \mathrm{O}_{3}$ & $\mathrm{Fe}_{2} \mathrm{O}_{3}$ & $\mathrm{CaO}$ & MgO & $\mathrm{Na}_{2} \mathrm{O}$ & $\mathrm{K}_{2} \mathrm{O}$ & $\mathrm{Cr}_{2} \mathrm{O}_{3}$ & $\mathrm{TiO}_{2}$ & Mno & $\mathrm{P}_{2} \mathrm{O}_{5}$ & SrO & $\mathrm{BaO}$ & LOI & Total \\
\hline DESCRIPTION & $\%$ & $\%$ & $\%$ & $\%$ & $\%$ & $\%$ & $\%$ & $\%$ & $\%$ & $\%$ & $\%$ & $\%$ & $\%$ & $\%$ & $\%$ \\
\hline $1 U N-30380,20$ & 49,8 & 13,35 & 15,2 & 9,53 & 5,47 & 2,67 & 0,41 & 0,02 & 2,28 & 0,21 & 0,22 & 0,01 & 0,02 & 1,72 & 100,91 \\
\hline $1 U N-30380,00$ & 47,9 & 12,4 & 17,1 & 6,57 & 5,7 & 2,8 & 0,38 & 0,01 & 2,22 & 0,16 & 0,22 & 0,02 & 0,01 & 3,43 & 98,92 \\
\hline
\end{tabular}

\section{CONCLUSÕES E CONSIDERAÇÕES FINAIS}

Os resultados petrográficos, químicos e litogeoquímicos do corpo intrusivo estudado apontam que sua composição se trata de basalto toleítico associado a derrames continentais. Os teores de $\mathrm{Mg}$, Fe e Ti sugerem o seu enquadramento em basaltos transicionais dentro da conhecida classificação de basaltos de baixo e
alto-Ti relacionados a derrames continentais (Peate et. al., 1992). Essas características estão de acordo com o contexto estratigráfico, estrutural e geotectônico das intrusões magmáticas da Bacia do Parnaíba anteriormente estabelecido por outros autores (Bellieni et. al., 1990; Vaz et. al., 2007; Merle et. al., 2011; Silva et. al., 2017). 
Os dados das análises químicas em microssonda eletrônica e as relações microtexturais sugerem a evolução magmática dessa intrusão como uma sequência de eventos ordenados desde a câmara magmática até depois de sua acomodação na rocha encaixante. Inicialmente, dentro da câmara magmática, houve uma primeira fase de cristalização que aconteceu de forma lenta. Nela foram formados os núcleos dos cristais de piroxênio e dos fenocristais de plagioclásio. Posteriormente, ocorreu uma dissolução parcial/corrosão e originou-se a textura em peneira grossa presente nos fenocristais de plagioclásio formados durante a fase de cristalização anterior. Essa feição, segundo Rentijh et. al. (2014), é decorrente de uma rápida descompressão do magma durante sua ascensão da câmara magmática. Tal ascensão caracteriza o segundo evento evolutivo do magma. A textura do tipo peneira fina, também de acordo com Rentijh et. al. (2014), é promovida por injeção de um novo magma mais quente, rico em cálcio, que se mistura com o líquido restante. Dessa forma, esse processo ocasionou a segunda fase de cristalização do plagioclásio, marcado pela presença de textura em peneira fina. Esta última etapa também deu origem à borda dos cristais de piroxênio.

No que se refere à rocha sedimentar encaixante, a observação de contatos intergranulares tangenciais e suturados apontam que o arenito, na zona próxima à região de contato com a intrusão, formou-se sob condições de forte diagênese.

Adicionalmente, a presença de tremolita e de outros minerais de anfibólio, que se estabilizam acima das condições diagenéticas, sugerem que a rocha também foi submetida a temperaturas ainda mais elevados que as da diagênese. Tais condições devem-se presumidamente ao contato com o líquido magmático. No entanto, a preservação de estruturas sedimentares primárias e ausência de quaisquer características indicativas de metamorfismo descartam a hipótese de a rocha ter passado por processos de metamorfismo de contato. Conclui-se então que a zona próxima ao contato com a rocha basáltica passou por um processo denominado como diagênese de contato.

O termo foi definido no trabalho de McKinley et. al (2001) para descrever as mudanças paragenéticas ocorridas nos arenitos do Grupo Sherwood Triássico e associadas, devido à falta de indicações claras de metamorfismo de contato, com a intrusão ígnea observada na área. A paragenese mineral descrita por ele incluía a predominância de minerais de anfibólio que são também observados em grande quantidade no arenito do poço aqui estudado. Da mesma forma, outros minerais observados como os argilominerais do grupo da esmectita, os minerais do grupo da clorita, a zeólita e o kfeldspato também foram relatados como produtos da diagênese de contato em seu e em outros trabalhos (Brauckmann \& Füchtbauer, 1983; McKinley et. al., 2001; Bernet \& Gaupp, 2005).

Apesar de ter nomeado todos os processos observados por eles como metamorfismo de contato, Brauckmann \& Füchtbauer (1983) descreveram uma paragenese mineral semelhante à de McKinley et. al. (2001) em algumas das amostras estudadas dos arenitos e siltitos da Formação Atane, na península de Nûssuaq na Groelândia, onde afirmaram hesitar em aplicar o termo metamorfismo para essas "regiões de fraca alteração, sugestivas que as temperaturas permaneceram menores que $200^{\circ}$ C". Em seu trabalho, esses autores associaram a formação de minerais como anfibólio e clorita ao $\mathrm{Mg}$, Fe e $\mathrm{Ti}$ proporcionado pelas intrusões basálticas, além do calor fornecido por elas. Também sugerem que a formação dos argilominerais do grupo esmectita aconteceu tardiamente, no período de resfriamento da intrusão.

\section{AGRADECIMENTOS}

Esta pesquisa foi realizada em associação com o projeto de P\&D "Suites basálticas da bacia do Parnaíba e suas relações com sistemas petrolíferos associados", registrado como ANP 19088-4 e Fundação COPPETEC IGEO-19.343, patrocinado pela Geopark Brasil com recursos da Participação Especial firmados pela ANP como "Compromisso de Investimentos com Pesquisa e Desenvolvimento".

\section{REFERÊNCIAS}

ABELHA, M. Bacia do Parnaíba. In: 12 ${ }^{\mathrm{a}}$ RODADA DE LICITAÇÕES DE PETRÓLEO E GÁS, ANP, 
Disponível em: http://rodadas.anp.gov.br/arquivos/Round_12/ Seminarios_R12/apresentacao/r12_04_parnaiba.pdf. Acessado em: 22 de maio de 2018.

AGUIAR, G.A. Revisão geológica da bacia paleozóica do Maranhão. In: CONGRESSO BRASILEIRODE GEOLOGIA, 25, 1971, São Paulo. Anais... São Paulo: Sociedade Brasileira de Geologia, 1971, v. 3, p. 113-122.

ALMEIDA, F. F. M.; BRITO NEVES, B. B.; CARNEIRO, C. D. R. The origin and evolution of the South American Platform. Earth Science Reviews, v. 50, p. 77-111, 2000.

BECCALUVA, L.; BIANCHINI, G.; NATALI, C.; SIENA, F. Continental Flood Basalts and Mantle Plumes: a Case Study of the Northern Ethiopian Plateau. Journal of Petrology, v. 50, n. 7, p. 1377-1403, 2009

BELLIENI, G.; COMIN-CHIARAMONTI, P.; MARQUES, L. S.; MELFI, A. J. PICCIRILLO, E. M.; NARDY, A. J. R.; ROISENBERG, A. High- and low-TiO2 flood basalts from Paraná Plateau (Brazil): petrology and geochemical aspects bearing on their mantle origin. Neues Jahrbuch Mineralogie Abhandlungen, v. 150, p. 273-306, 1984.

BELLIENI, G.; PICCIRILLO, E. M.; CAVAZZINI, G.; PETRINI, P.; COMIN-CHIARAMONTI, P.; NARDY, A. J. R.; CIVETTA, A. J.; MELFI, A. J.; ZANTEDESCHI, P. Lowand high $\mathrm{TiO} 2$, Mesozoic tholeiitic magmatism of the Maranhão basin (NE-brazil) - K-Ar age, geochemistry, petrology, isotope characteristics and relationships with Mesozoic low- and high TiO2 flood basalts of the Paraná Basin (SE-Brazil). Neues Jahrbuch Mineralogischer Abhandlungen, v. 162, p. 1-33, 1990.

BERNET, M. \& GAUPP, R. Diagenetic history of Triassic sandstone from the Beacon Supergroup in Central Victoria Land, Antarctica. New Zealand Journal of Geology and Geophysics, v. 48, n. 3, p. 447-458, 2005.

BOND, G.C.; NICKESON, P. A.; KOMINZ, M.A. Breakup of a supercontinent between $625 \mathrm{Ma}$ and $555 \mathrm{Ma}$ : new evidence and implications for continental histories. Earth and Planetary Science Letters, v. 70, n. 2, p. 325-345, 1984.

BRAUCKMANN, F. J. \& FÜCHTBAUER, H. Alterations of cretaceous siltstones and sandstones near basalt contacts (Nûgssuaq, Greenland). Sedimentary Geology, v. 35, p. 193213, 1983.

CHIPERA, S.J. \& APPS, J.A. Geochemical Stability of Natural Zeolites. Reviews in Mineralogy and Geochemistry, v. 45, n. 1, p. 118-161, 2001.

DA SILVA, A. G.; ALMEIDA, C. N.; VALENTE, S. DE C.; BORGHI, L. F. Petrogênese de diabásios toleíticos na porção oriental da Bacia do Parnaíba: evidências para heterogeneidade no manto litosférico subcontinental no NE do Brasil. Brazilian Journal of Geology, v. 47, n. 1, 2017.

DEER, W. A.; HOWIE, R. A.; ZUSSMAN, J. (Autores). SingleChain Silicates (Rock-Forming Minerals). Geological Society of London, 680p., $2^{a}$ edição, 1997.

DOTT, R.H. (Autor). Wacke, Greywacke and Matrix-What Approach to Immature Sandstone Classification? Journal of Sedimentary Petrology, v. 34, p. 625-632,1964.

ESPOSITO, K. J. \&WHITNEY, G. (Autores). Thermal Effects of Thin Igneous Intrusions on Diagenetic Reactions in a Tertiary Basin of Southwestern Washington. U.S. Geological Survey, Information Services, 40p., 1995.
GOES, A.M.O.; SOUZA, J.M. P.; TEIXEIRA, L.B. Estágio exploratório e perspectivas petrolíferas da Bacia do Parnaíba. Boletim de Geociências da Petrobras, v. 4, p. 5564, 1990.

LE MAITRE, R. W. (Autor). A Classification and Glossary of Terms: Recommendations of the International Union of Geological Sciences Subcommission on the Systematics of Igneous Rocks. Edimburgo. Cambridge University Press, 2. ed., p. 236, 2002.

LEITE, J.F.; ABOARRAGE, A. M.; DAEMON, R. F. Projeto Carvão da Bacia do Parnaíba. Relatório final das etapas II e III. DNPM/CPRM, Recife, 1 v., 1975.

MCKINLEY, J. M.; WORDEN, R. H.; RUFFELL, A. H. Contact diagenesis: the effect of an intrusion on reservoir quality in the Triassic Sherwood sandstone Group, Northern Ireland. Journal of Sedimentary Research, v. 71, n. 3, p. 484-495, 2001.

MERLE, R.; MARZOLI, A.; BERTRAND, H.; REISBERG, L.; VERATI, C.; ZIMMERMANN, C.; CHIARADIA, M.; BELLIENI, G.; ERNESTO, M. 40Ar/39Ar ages and $\mathrm{Sr}-\mathrm{Nd}-$ $\mathrm{Pb}-\mathrm{Os}$ geochemistry of CAMP tholeiites from Western Maranhão basin (NE Brazil). Lithos, v. 122, n. 3-4, p. 137-151, 2011.

McKINLEY, J. M.; WORDEN, R. H.; RUFFELL, A. H. Contact diagenesis: the effect of an intrusion on reservoir quality in the triassic Sherwood Sandstone Group, Northern Ireland. Journal of Sedimentary Research, v. 71, n. 3, p. 484-495, 2001.

OLIVEIRA, D. C. \& MOHRIAK, W. U. Jaibaras trough: an important element in the early tectonic evolution of the Parnaíba interior sag basin, Northern Brazil. Marine and Petroleum Geology, v. 20, n. 3-4, p. 351-383, 2003.

PEATE, D.; HAWKESWORTH, C. J.; MANTOVANI, M. Chemical stratigraphy of the Paraná lavas (South America): classification of magma types and their spatial distribution. Bulletin of Volcanology, v. 55, n.1, p. 119-139, 1992.

PEATE, D. \& HAWKESWORTH, C. J. Lithospheric to asthenospheric transition in Low-Ti flood basalts from southern Parana, Brazil. Chemical Geology, v. 127, n. 1-3, p. 1-24, 1996.

RENJITH, M.L. Micro-textures in plagioclase from 1994-1995 eruption, Barren Island Volcano: Evidence of dynamic magma plumbing system in the Andaman subduction zone. Geoscience Frontiers, v. 5, p. 113-126, 2014.

STRECKEISEN, A. To each plutonic rock its proper name. Earth Science Reviews. v. 12, p. 1-33, 1976.

THOMPSON, T. W.; LIU, W. T.; WEISSMAN, D. E. Synthetic aperture radar observation of ocean roughness from rolls in an unstable marine boundary layer. Geophysical Research Letters, v. 10, n. 12, 1983.

VAZ, P.K.; REZENDE, N. DAS G. DE A. DA M.; FILHO, J. R. W.; TRAVASSOS, W. A. S. Bacia do Parnaíba. Boletim de Geociências da Petrobrás, v. 15, p. 253-263, 2007.

Submetido em 5 de junho de 2019 Aceito para publicação em 3 de junho de 2020 